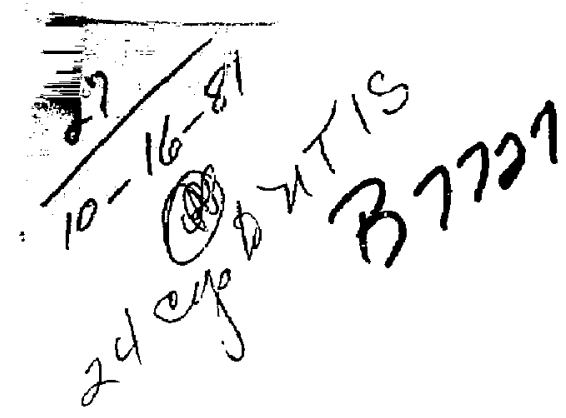

\title{
MASTER
}

UCID- 19197

\section{ATA INJECTOR-GUN CALCULATIONS}

A. C. Paul

August 3, 1981

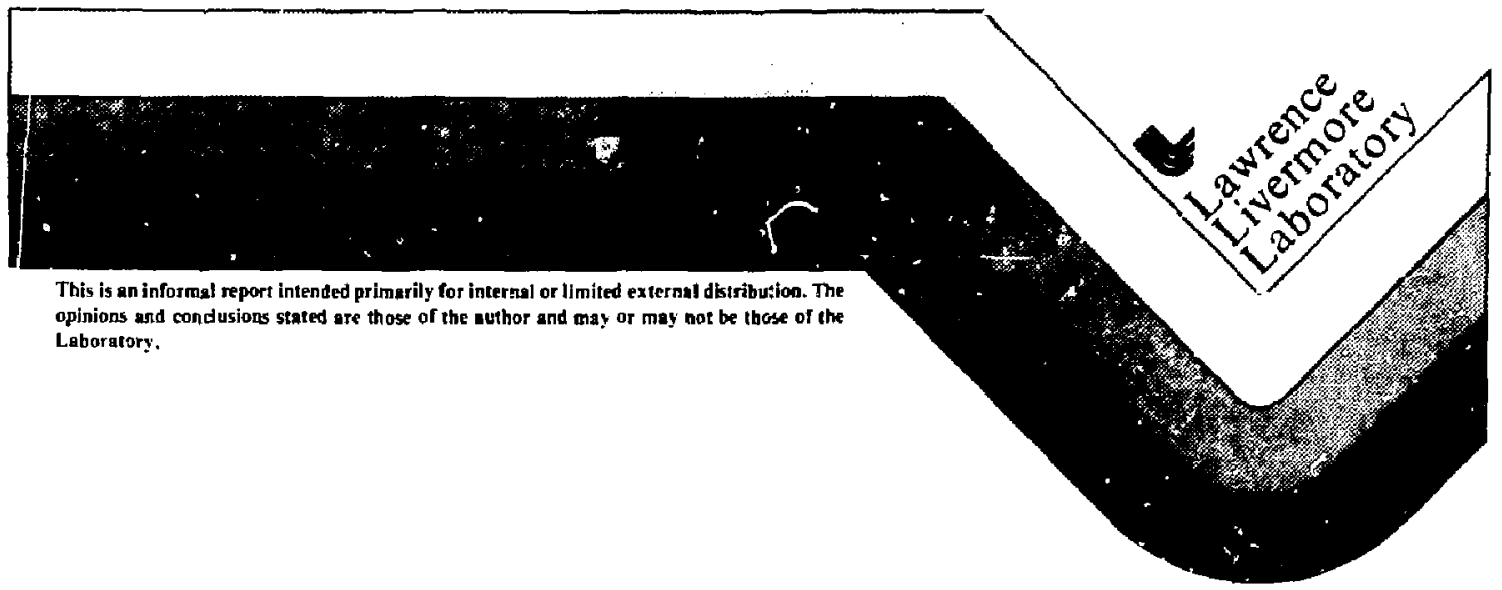

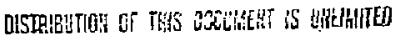


ATA INJECTOR GUN CAL CULATIONS

A. C. Paul

Lawrence Livermore National Laboratory*,

University of California,

Livermore, California $9 \Delta 550$

\section{ABSTRACT}

ATA is a pulsed, 50 ns $10 \mathrm{KA}, 50 \mathrm{MeV}$ linear induction elect on accelerator at LLNL. The ETA ${ }^{\top}$ could be used as an injector for, $\lambda$. However the possibility of building a new injector gun for ATA, raised the question as to what changes from the ETA gull in electrode dimensions or poteritials, if any, should be considered. In this report I will review the $E B Q^{2}$ code results for the four electrode configurations of $F i g$. I an attempt to determine the geometrical scaling laws appropriate to thes- ETA type gun geometries. Comparison of these scaling laws will be made te ETA operation. The characteristic operating curves for these geometries will also be presented and the effect of washer position determined. It will be shown that emittance growth will impose a limitation on beam current for a given anode potential before the virtual cathode limit is reached.

\section{GEOMETRIES}

The ATA injector will be similar to the ETA injector at LLNL, which has been in operation since 1979. The ETA injector consists of a cold plasma cathode from which the electrons are extracted by a planar grid, Fig. 1.

\footnotetext{
*The Lawrence Livermore National Laboratory is operated by the University of California for the Department of Energy under Contract No. W-7405-Eng-48.

This work is performed by LLNL for the Department of Defense under DARPA (DOD) ARPA Order $3 / 78$, Amendment $\# 33$ and 34 , monitored by NSWC under Contract NO. N60921-81-LT-W0009, Amendment No. 1 and N60921-81-LT-W0026.
}

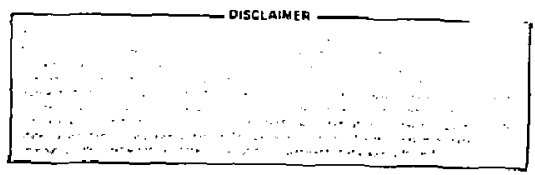


These electrons are self-focused by their own magnetic field near the grid. External solenoid focusing is provided after the beam enters the anode.

The longitudinal coordinate origin is at the gun cathode. The bean calculations for this injector extend a sufficient distance down stream $(60 \mathrm{~cm})$ to allow evaluation of the beam behavior into the anode bore, approximately at $20 \mathrm{~cm}$. Four geometries have been calculated over a range of anode and grid potentials so as to gain insight into the performance of the gun when the electrode potentials are varied or as these potentials change with time from nomiral, fixed-flat-top conditions. In these calculations the anode potential häs been chosen fixed in $1 / 2$ MV steps while the grid voltage was varied to determine the decelerative (D) threshold and virtual cathode (VK) threshold to within a resolution in grid potential of $1 \mathrm{kV}$.

The first geometry considered is that of the ETA gun with a 10 inch diameter cathode and a cathode anode separation of $22.4 \mathrm{~cm}$. The washer is midway between the cathode and anode and is at half the anode potential. The second geometry is the ETA with a $4 \mathrm{~cm}$ reduction in the cathode anode separation. The washer is still midway between the cathode and the anode. No other changes were made between the configurations of geometries 1 and 2 . In geometries 3 and 4 the cathode diameter has been reduced to 8 inches. In geometry 3 the longitudinal dimensions have not been reduced from the ETA dimensions. In geometry 4 all dimensions have been reduced by $80 \%$ from ETA, resulting in an 8 inch cathode, and 18 cin cathode anode separation, Fig. 1.

DYNAMIC OPERATION OF GUN

The beam current anode voltage curve of the qun divides the operation into two distinct regions. Operation above the curve is in the virtual 
cathode domain, operation below the curve should yield a stable beam of reasonable emittance with results predictable by computer simulations. In actual operation the voltages on the grid and anode are time dependent and the operating point of the gun, indicated as the black dot in $\mathrm{Fig}$. $2 \mathrm{~A}$ can be reached via three fundamentally different paths as shown. These paths differ only in the time the grid is fired relative to the anode. The beam current at the flat top of the anode waveform is determined by the grid voltage achieved at the flat top of the grid pulse.

Path $A$ represents triggering the grid after the anode has achieved its $f$ lat top so that the beam current rises from zero to full value at $V_{a}$. Path B represents the path followed when the grid is triggered simultaneously with the anode, $F i g .2 B$. The beam current follows a $v_{g} 3 / 2$ power law which keeps it below the anode 7 imiting current at all times. Path $C$ represents the path followed when the grid is triggered before the anode. Here the beam current may exceed the acceptable anode ccrrent and consequently represent operation in the virtual cathode resime for some time.

The presence of the external focusing solenoids puts a requirement on the minimum energy the beam can have and still penetrate the catcher coil field. This requires the beam to be on the right of the vertical line shown at approximately $v_{a} / 2, F i g .2 A$. The requirement that the beam have sufficient energy and be below the virtual cathode current limit restricts the region of operation on the current voltage diagram to the shaded area shown, and implies that the grid should be triggered after the anode, just about as the anode is is flat top. 
RESIMES OF OPERATION

In the absence of beam, the potential on axis rises from that of the grid to that of the anade well inside the anode bore. If the bore of the anade is infinitesimal in comparison to the grid anode separation, the potential rises linearly with 2 . As the anode bore is increased the potential rise becomes more gentle, assumptotically approaching the anode value many anode bores inside the anode. When beam is present, the electric self-field of the beam depresses this axial value of the electrode potential in the grid anode space.

The beam current injected inco the grid anode space is determined by the C ifd-Langmuir law applied to the cathode grid diode. If this current is too high, a potential drop will occur just past the grid. Onset of this potential drop defines the threshold for the deceleration resime of gun operation, Fig. 3. The limiting current is reached when a virtual cathode is formed. The threshold of the decelerative resime occurs at approximately $80 \%$ of the virtual cathode current for all geometries studied in this report, Fiạ. 4.

\section{CHARACTERISTIC CURVES}

A plot of the EJA grid voltage required to just form a virtual cathode is shown in Fig. 5. The virtual cathode threshold current injected into the grid anode space by this grid voltage is shown in Fig. 6 . The virtual cathode threshold of the ETA gun has been raised by $10 \%$ from that previously reported. ${ }^{3}$ This resulted from improvements in the algorithm for calculation of the electric fields near electrodes in the EBQ code. In the previous calculations the beam energy was a few keV below the grid potential on passage through the grid. The electrons therefore had a velocity which was too low, 
resulting in the deposition of too much charge on the mesh. The impulse on the beam from this charge was also too large. The net compounded effect was a $10 \%$ error in the virtual cathode threshold. Figure 5 and 6 give the virtual cathode threshold for the old and new ETA calculations as grid vs. anode voltage and beam current vs. anode voltage curves. The dashed curves are for $80 \%$ of the virtual cathode threshold current and represent the onset of the deceleration resime beyond the grid.

The virtual cathode curves for all four of the geometries studied are shown in Figs. 7 and 8 . The geometries are labeled by the cathode diameter/cathode anode separation. The smaller the cathode ariode separation, the higher the longitudinal axial electric field and the higher the virtual cathode threshold. For a given anode position and voltage, the larger the cathode, the higher the virtual cathode threshold, Fig. 8.

POSITIONING THE WASHER

The presence of the washer at half the anode potential approximately midway between the cathode and anode serves several purposes: 1) it increases the axial electric field on axis near the grid resulting in a higher virtual cathode threshold than possible without the washer: 2) it a?lows limited electrostat ic focusing of the low current full energy beams. Moving the washer towards the anode provides additional electrostat ic focusing for the low current beams but reduces the on axis axial electric field and therefore reduces the virtual cathode limit for a given anode potential. Figure 8 shows the effect of moving the washer from 11.2 to $13.2 \mathrm{~cm}$ for the 8 and 10 inch cathode characteristic curves with $22.4 \mathrm{~cm}$ anode cathode separation operated at $2.5 \mathrm{MV}$. 
The $10-$ inch $/ 22 \mathrm{~cm}$ curve with the washer at $11.2 \mathrm{~cm}$ drops from $14.5 \mathrm{kA}$ to $12.5 \mathrm{kA}$ when the washer is moved to $13.2 \mathrm{~cm}$ while the $8-i n c h / 22 \mathrm{~cm}$ curve with the washer at $13.2 \mathrm{~cm}$ rises from $10.2 \mathrm{kA}$ to $12.2 \mathrm{kA}$ when the washer is moved to $11.2 \mathrm{~cm}$.

The sequence of beam profiles for the ETA gun operating at 2.5 MV anode as the grid potential is increased, injecting more and more beam into the grid anode space is shown in Fig. 9. Virtual cathode formation for this washered configuration occurs at $93 \mathrm{kV}$ and is $14.77 \mathrm{kA}$. Figure 10 shows the same standard ETA gun geometry without the washer. The sequence of frames is for jncreasing grid voltage resulting in the formation of a virtual cathode at 74 $k V$ grid, or a current of $10.514 \mathrm{kA}$. This is a reduction in the virtual cathode 1 imit of $29 \%$ from the washered case.

Moving a washer toward the anode provides additional electrostatic focusing for the low current beams, Fig. 11, but reduces the on-axis axial electric field and therefore reduces the virtual cathode limit for a given anode potential, Fig. 12.

ETA experience has shown that the machine works without the washer. The evidence is that beam lost on the washer may upset the voltage balance of the gun and as such does more degradation of performance than the presence of the washer helps in improving performance. Should this situation stand the test of time, it may be useful to use a washer of larger aperture, as shown in Fig. 13. Here the washer bore is $14.5 \mathrm{~cm}$ compared to the 12.7 bore of Fig. 9. The larger aperture should reduce beam loss on the washer while maintaining a mid point potential. The virtual cathode limit for this case occurs at $87 \mathrm{kV}$ and is 13,382 amps, or $9 \%$ lower than the configuration of Fig. 9 . 
The position of the washer within the grid-anode space has been varied and its effect on the virtual cathode limit given in Table 1. These results are for operation at $2.5 \mathrm{MV}$ anode with a grid cathode separation of $1.5 \mathrm{~cm}$. The cathode is located at $z=0$, and anode and washer position measured downstream from the cathode. In this table the virtual cathode grid voltage is expressed as $V_{1} / V_{2}$ giving a virtual cathode current of $I_{1} / I_{2}$. $V_{1}, I_{1}$ is below the virtual cathode limit and $V_{2}, I_{2}$ is above the virtual cathode limit and represents the resolution of the calculations, namely the $1 \mathrm{kV}$ increment on the grid used to identify virtual cathode formation.

GUN CONDUCTANCE

The beam current defining virtual cathode threshold can be expressed as a quadratic polynomial in the anode potential, as suggested by the shape of these characterist ic cures, $F$ ig. 8.

$$
I_{a}=a v_{a}+b v_{a}^{2}
$$

The EBQ calculations were performed to a $1 \mathrm{kV}$ resolution in the grid potential required to cross the virtual cathode line. This $1 \mathrm{kV}$ grid resolution translates into an uncertainty in the team current for a given anode potential $V_{a}$. For a given anode potential, take $I_{u}$ as the current above the virtual cathode line and $I_{b}$ the current below the virtual cathade line associated with this $1 \mathrm{kV}$ grid resolution. Then we may define the virtual cathode current at this anode potential as 


$$
I_{v k}=\frac{1}{2}\left(I_{u}+I_{b}\right) \pm \frac{1}{2}\left(I_{u}-I_{b}\right)
$$

with the uncertainty $\Delta=\frac{1}{2}\left(I_{u}-I_{b}\right)$. We solve for the coefficients $a, b$, of Eq. I by choosing two potentials $v_{a}=v_{1}$ and $v_{a}=v_{2}$ with their limiting virtual cathode currents $I_{v k}$ of $I_{1}$ and $I_{2}$ with uncertainties $\Delta_{1}$ and $\Delta_{2}$, then

$$
\begin{aligned}
& a=\frac{I_{1} v_{2}^{2}-I_{2} V_{1}^{2}}{V_{1} V_{2}\left(V_{2}-V_{1}\right)} \pm \frac{\Delta_{1} V_{2}^{2}-\Delta_{2} V_{1}^{2}}{V_{1} V_{2}\left(V_{2}-V_{1}\right)} \\
& b=\frac{V_{1} I_{2}-I_{2} I_{1}}{V_{1} V_{2}\left(V_{2}-V_{1}\right)} \pm \frac{\Delta_{2} V_{1}-\Delta_{1} V_{2}}{V_{1} V_{2}\left(V_{2}-V_{1}\right)}
\end{aligned}
$$

The possible range in $a$ and $b$ introduced by these uncertainties are given by the second terms in the two preceding equations with $\Delta_{1}$ and $\Delta_{2}$ chosen with opposite signs.

For all four geonetries, the quadrat ic coefficient, $b$, is small in comparison to the linear coefficient, a. Retention of only the first term is justified in the expression of $I$ as a function of the anode potential for the ETA cathode anode separation of $22.4 \mathrm{~cm}$ where the quadratic term is zero within the resolution of the calculations.

$$
I=\mathbf{a} V_{a}
$$

For the $18 \mathrm{~cm}$ cathode anode separation, neglect of the quadratic term amounts to an error of less than $10 \%$ for anode potentials to $3 \mathrm{MV}$. The range of this 
uncertainty produced by the $1 \mathrm{kV}$ grid resolution is shown by the error cars on Fig. 6. For the $18 \mathrm{~cm}$ anode cathode spacing

$$
I=a v_{a}-b v_{a}^{2}
$$

The conduct ance of the gun, $a$, and nonlinearity, $b$, for these geometries are given in Table?.

GUN GEOMETRY SCALING

For a one dimensional diode, the beam current scaling with cothode radius and anode gap is given by the Childs-Langmuir law so that for a given fixed anode voltage, the current times the square of the ratio of anode separation to $c$ athode radius is constant. For the ETA-ATA gun dimensions, we find that the current times the ratio of the anode-grid spacing to cathode radius is constant as shown in Table 3 for the various gun configurations studied. All cases in Table 3 are for $2.5 \mathrm{MV}$ anode potential and a cathode grid spacing of $1.5 \mathrm{~cm}$. The virlual cathode current, $I_{v k}$ scales directly as the ratio of the cathode radius to grid anode separation

$$
I_{v k}=\frac{r_{k}}{z_{a}-{ }^{2} g}
$$


where $r_{k}$ is the cathode radius, $z_{a}$ anode position, $z_{g}$ grid position, and b, a numerical constant equal to 24 for ETA operation at $2.5 \mathrm{MV}$.

\section{BEAM EMITTANCE}

There are several contributions to beam emittance in the ETA-ATA gun design. The main sources are filamentation from the lens action of finite grid wires, pierce correction, spherical aberration of the anode, and coherent growth close to the virtual cathode threshold.

Simulation of the effect of the finite grid wires requires use of a $f$ ine computer mesh to allow resolution of the detail on a scale determined by the grid wire spacing. ${ }^{4}$ Expansion of the first few $\mathrm{cm}$ of the gun can be achieved by fixing an artificial boundary along some equipotential in the grid anode space. This equipotential must be calculated from a solution of Poissons equation including the space charge of the beam. Figure 14 shows chese equipotentials on a coarse mesh upon which a self consistant 11 kA solution has been obtained. The $250 \mathrm{kV}$ surface is used as the "anode" boundary for the expansion region around the $80 \mathrm{kV}$ grid wire run shown in Fig. 15. The wire spacing is $1 / 2 \mathrm{~cm}$. The phase plot $x-x^{\prime}$ at the $250 \mathrm{kV}$ surface where all particles have the same energy and therefore the same $B$ and $Y$ is shown in $F i g$. 16. The area, $A$, of a circumscribed figure arcund the individual particles is $\pi$ times the product of the invarient points $x_{1}$ $x_{i}^{\prime}$ shown in the figure. The normalized enittance $E$ is defined as

$$
E=\frac{A}{\pi B Y}
$$


and can be readily found from the figure to be $580 \mathrm{~cm}-\mathrm{mr}$. This two dimensional simulation does not include the reduction of the transverse electric fields near the radial strings supporting the concentric grid wire rings. The actual emittance should be about half the value calculated from this two dimensional simulation.

$$
E=300 \mathrm{~cm}-\mathrm{mr}
$$

SPHERICAL ABERRATION

We now investigate the contributions to beam emittance produced by the spherical aberration of the anode aperature and the beam self forces, in particular, the change in emittance as the virtual cathode threshold is approached.

For an ideal simple lens of focal length $f$, the angular divergence for a ray in the beam is proportional to the radial displacement $r$. This translates into a straight 7 ine in the phase space, Fig. 17, of slope equal to the reciprocal of the focal length. For a diverging lens, the slope is positive, for a converging lens the slow: is negative.

Real lenses suffer for many nonideal screw ups. Spherical aberration, for one, contributes to the anguiar displacement a term cubic in the radial displacement acquired in the ?ens, Fig. 18.

$$
r^{\prime}=a r+b r^{3}
$$


For the real lenses, $b$ is always positive as the lense strength increases the further out in the lens the rays go.

The spherical aberration of the electrostatic axiajly symmetric lense encuuntered on entrance to the ETA gun anoois is characterized by the nonlinearity it introduces into the defocusing of the beam. If we express the divergence of the beam after passage through the lense as a polynomial in transverse position, then all even powers must vanish as a consecuence of the assumed axial symmetry.

The value of the coefficient $a$, of the linear term in the expression of the radial slope on position is a measure of the strength of the lense and consists of those terms from external focusing (or defocusing) elements and self magnetic focusing. In and around the grid, the beam is self focused. Neglecting for the moment the charge build up near the grid as the beam approaches the virtual catnode limit, the bigher the current, the stronger the self magnetic pinch, and therefore, the stronger the self-focusing and the more negative the value of $a$, that is, the stronger the self-focusing of the beam.

At $20 \mathrm{~cm}$, just inside the anode bore, the beam has passed through a waist and is now diverging. Figure 19 shows the phase space at this location for a $2.5 \mathrm{MV}$ anode potential as the grid potential is varied. At $70 \mathrm{kV}$ grid, the beam current is quite low for this anode potential. Note the inner portion of the plot is linear and deviates from the straight reference line in the outer portion only, Fig. 20. This is the spherical aberration of the anode bore. Observe that the outer portion of the higher current phase plots have progressively larger negative slopes resulting from the stronger self-focusing of these beams near the grid. As one approaches closer and closer to the 
virtual cathode limit, the central portion of the beam experiences a stronger and stronger radially defocusing force from the accumulat ing charge near the axis close to the grid. Observe the inner portion of the high rurrent phase plots, Fig. 19 and 20, with progressively larger positive slopes. The defocusing of the inner portian of the beam comes from the charge buildup on axis near the grid as the virtual cathode limit is approached. Writing the slope of the phase space contribution for coherent virtual cathode approach as a polynomial in radial position

$$
r^{\prime}=a r+b r^{3}
$$

In the proximity of the grid, aperated far from the virtual cathode limit, a $<0$ and $b=0$. Close to the virtual cathode limit, $a>0$ and $b<0$. Thus the coherent effects just beyond the grid contribute effective emittance to the beam and appear as negative spherical aberration, e.g., $b<0$.

is the extend operation from the accelerative resime further and further into the decelerative resime, the defocusing of the central portion of the beam increases, resulting in a hollowing of the radial beam profile. The humping of the phase space here, results in an increase of the beam emittance. As an attempt to parameterize the gun operation we should note that this coherent emittance growth occurs on the characteristic curves between the decelerative and virtuai cathode thresholds.

The combined effect of emittance growth close to the virtual cathode formation and spherical aberration on the emittance of the beam is shown in Fig. 21. The emittance has been normalized and piotted against lorigitudinal position. The grid is at $1.5 \mathrm{~cm}$ and the anode is at $18 \mathrm{~cm}$. At small currents 
the emittance grows after entry into the anode as a result of spherical aberration. At currents just below virtual cathode formation the emittance is spoiled by the coherent growth just passed the grif. At intermediate currents, the emittance is best from partial cancellation of the coherent growth and the anode spherical aberration. Note particularly the minimum emittance at $95 \mathrm{kV}$ operation.

Beams of good emittance will be easier to tune and transport thraugh external magnets and acceleration cells. This combined with the desire to have the largest possible current will probably lead to operation of the gun at a grid potential which minimizes the emittance, Fig. 22. Higher grid voltage increases the beam current but this brings about a rapid growth in emittance. It appears therefore, that opt imum operation occurs above the decelerative threshold, but considerably below the virtual cathode threshold. From Figs. 7, 8, and 22 for ETA at 2.5 hN we have the results given in Table 4 .

COMPARISON OF ETA OPERATION WITH VIRTUAL

CATHODE CALCULATIONS

Combining the scaling laws Eq. 5 with $a=5.85 \pm .25 \mathrm{kA} / \mathrm{MW}$ and Eq. 7 with $b=24$ with the effect of the washer position measured by the parameter $i$, we obtain

$$
i_{v k}=9.60 \frac{r_{k}}{z_{\bar{a}}-z_{g}} f v_{a}
$$


$i_{v k}$ in $k A$ and $v_{a}$ in $M V$. For a gun without a washer, $f=0.7$. For the ETA gun with the washer at $1 / 2$ anode potential, midway between the cathode and anode, $f=1$. For other washer positions $f$ spans the range $0.7 \rightarrow 1$.

At $80 \%$ of the virtual cathode threshold, the beam begins to decelerate after passage through the grid. The calculations indicate that minimum beam emittance should occur somewhere between the onset of deceleration and virtual cathode formation. The resulting range of gun current for the ETA experimental conditions ( $2 \mathrm{MV}$ anode, $\mathrm{z}_{\mathrm{a}}=22.4 \mathrm{~cm}, \mathrm{z}_{\mathrm{g}}=1.5 \mathrm{~cm}$ ) then should be given by Eq. 11 , as $i_{D}=9.33 \mathrm{kA}<j<i_{v k}=11.7 \mathrm{kA}$.

This range if operating currents has been marked on a modif ied version of viewgraph 40.F.-13, Fig. 24 depicting the experimental operation for the indicated parameters. The label VK designates the virtual caihode threshold and the label $D$ designates the decelerative threshold.

Comparison bitween the calculated currents and the operationaily observed currents for these three cases will have to be subject to interpretation.

- The washered conf iguration may have been subject to be im loss on the washer, lowering its potential and consequently lowering the virtual cathode threshold.

$x \quad$ The cathode current for this case appears to be at or near the virtual cathode limit where emittance growth would be large. Note the poor transmission down the accelerator.

The cathode current for this case appears to be near the virtual cathode limit, however the good transmission down the accelerator 
precludes this as a virtual cathode example. The explanation may be that the anode voltage was higher than the $2 \mathrm{MV}$ quoted in the figure (measurement). Note that at an anode potential of $2.2 \mathrm{MV}$, 10\% above that quoted in the figure, the virtual cathode limit for this case would be $6.3 \mathrm{kA}$ rather than $5.7 \mathrm{kA}$. 


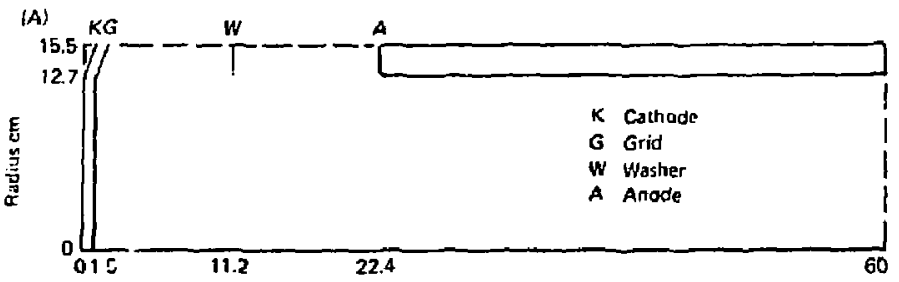

(B)

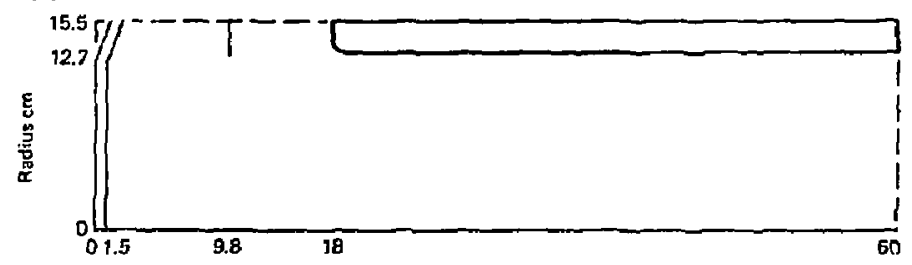

(C)

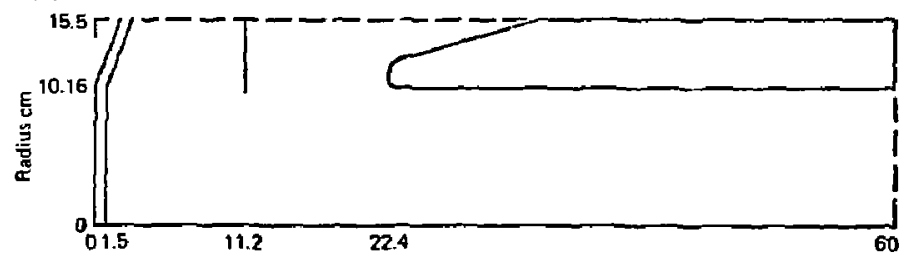

(D)

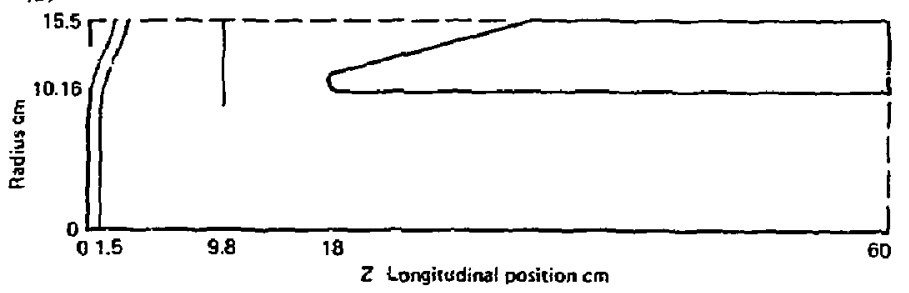

FIGURE 1. The four geometries considered in this report:

A) Original ETA geometry with 10 inch cathode and anode at $22.4 \mathrm{~cm}$ indicated as 10/22.

B) ETA with anode at $18 \mathrm{~cm} \mathrm{10/18.}$

C) Ejght-jnch dianeter cathode with anode at $22.4 \mathrm{~cm}, 8 / 22$ and

D) Eight-inch cathode with anode at $18 \mathrm{~cm} 8 / 18$. 

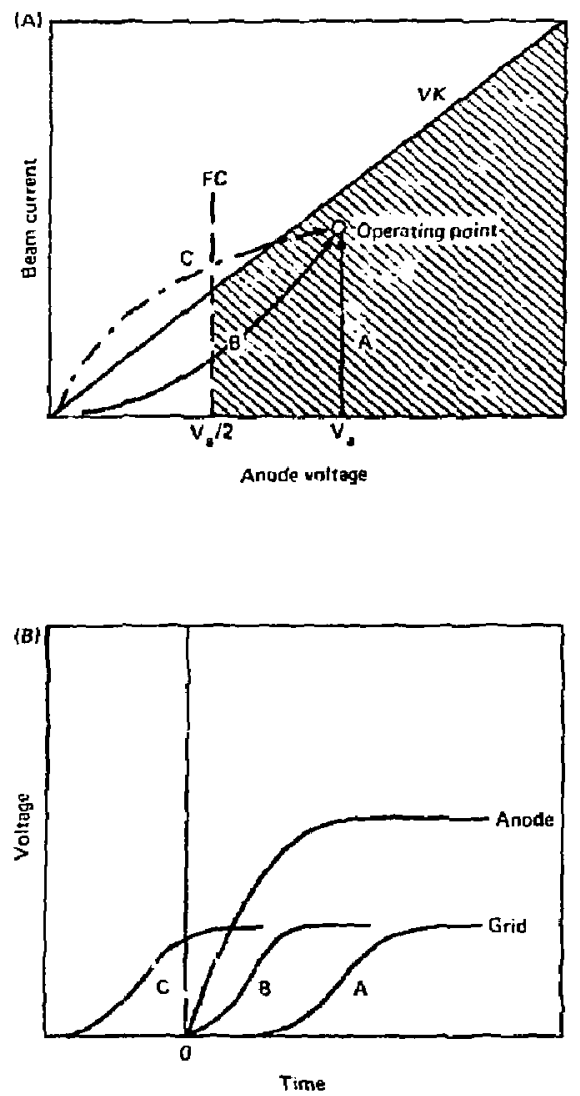

FIGURE 2.

A) For a given flat top anode potential $V_{\lrcorner}$, gun operation must be at a current below the virtual cathode lise VK and at a potential above the focusing coil cutoff line FC. This should restrict operation of the gun ai all times to the shaded area, even when the anode deviates from the desired value $v_{a}$.

B) In actual operation, the anode is turned on at time $T=0$. The potentia] rises from zero to the sum flat top value $V_{a}$. The grid can be turned on after the anode has reached the flat top $A$, simultaneously with the anode $B$, or before the anode $C$. The operating point in the current anode voitage space moves with time for these three grid turn-on times as indicated by curves $A, B$, and $C$ in $A$. 


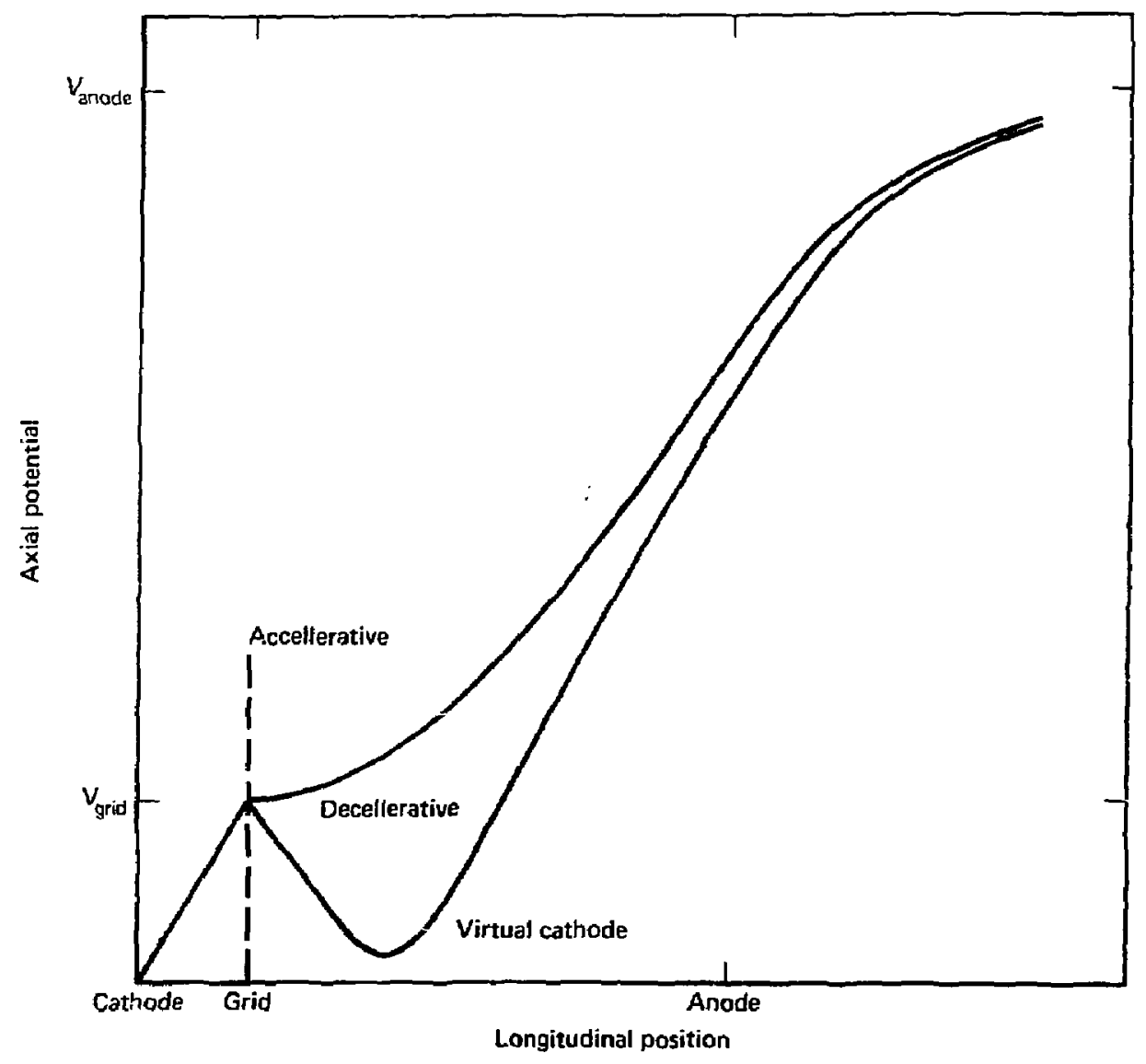

FIGURE 3.

The axial potential in these guns varies with longitudinal position. This variation can be used to define a declarative and virtual cathode threshold in the gun operation. For sufficiently small beam currents, the potential rises everywhere, starting at zero at the cathode and finally approaches that of the anode. This defines operation in the accelerative resime. As the beam current is increased, the potential drops from the grid value to a minimum before beginning its rise. This drop to a minimin: jecelerates the beam and operation here is in the decelerative resime. W- 2 the beam current is sufficiently high, a virtual cathode may form just beyound the grid. Any current above the virtual cathode threshold will result in the formation of a virtual cathode. 


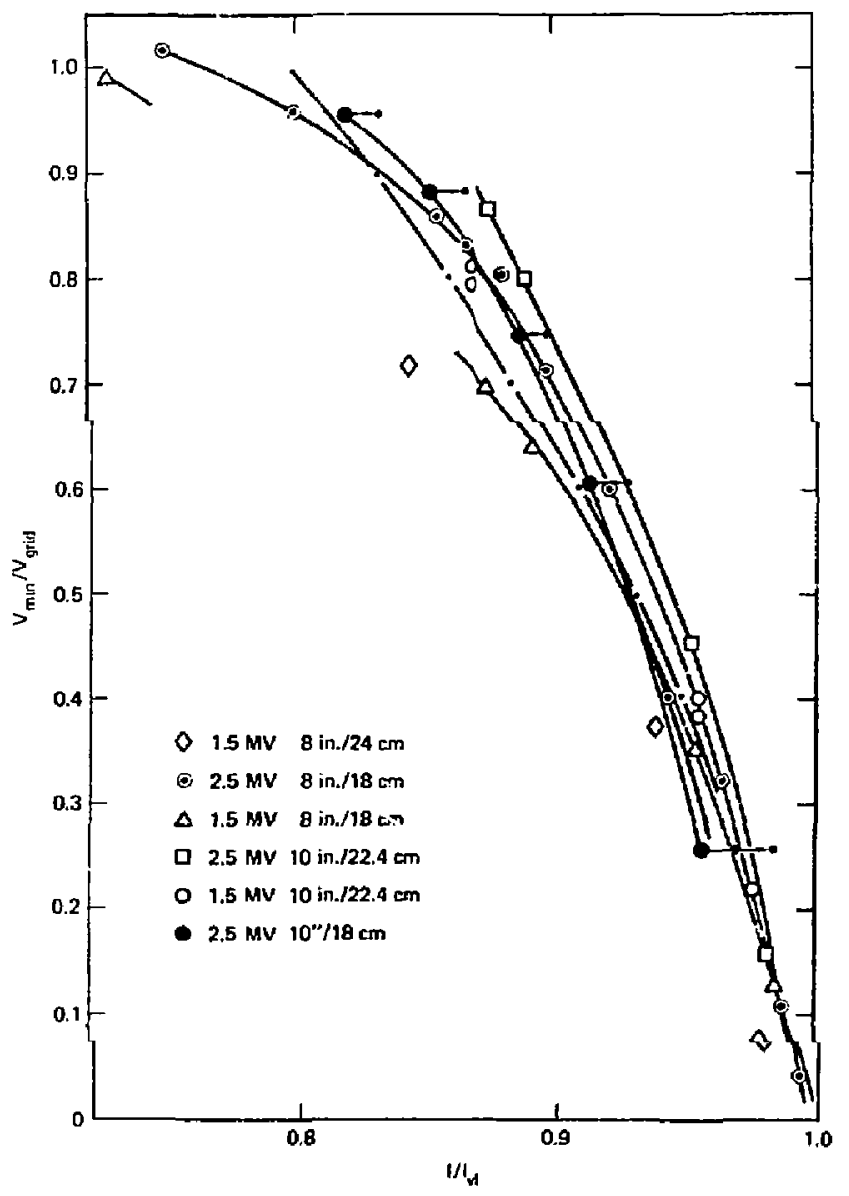

FIGULRE 4.

Ratio of minimum axial potential $V_{m i n}$, to the grid potential Vgrid vs the ratio of the beam current I, to virttal cathode threshold current Ivk. Different curves are for different geometries and different anode potentials. The decelerative threshold, $V_{\min } / V_{g r i d}=1$ occurs at approximately $80 \%$ of the virtual cathode threshold current for all geometries considered. 


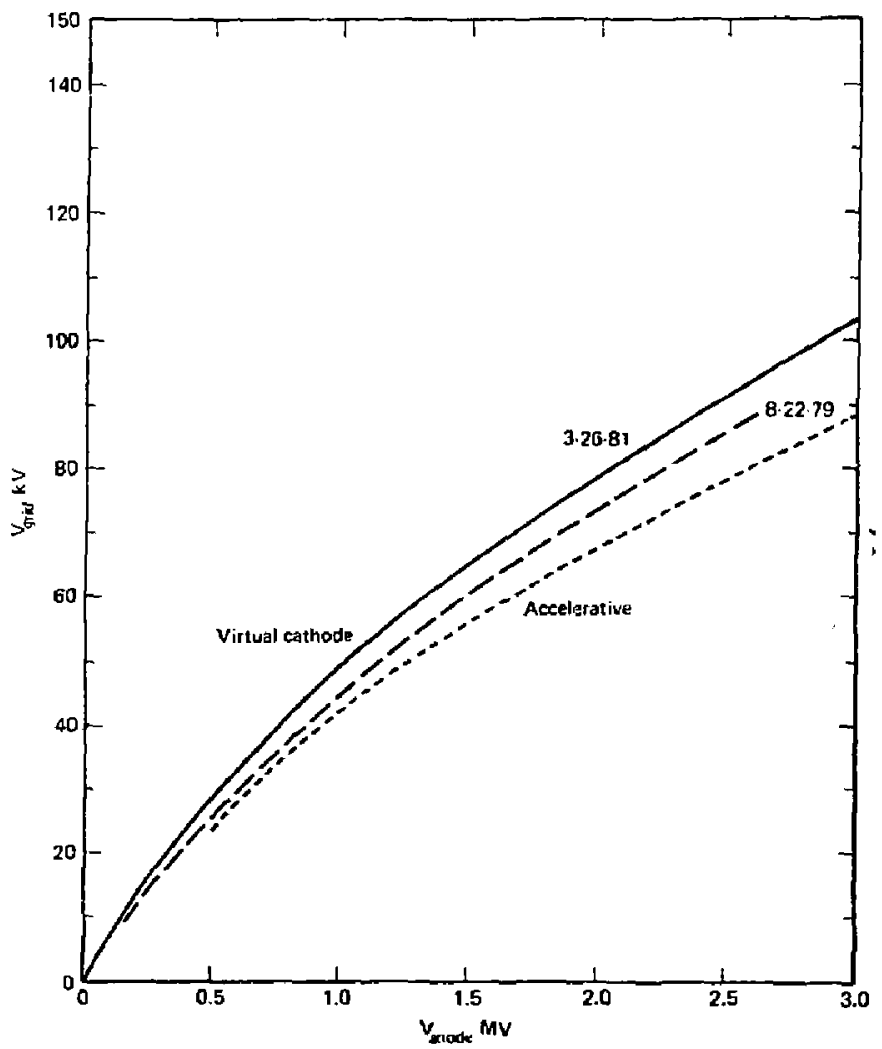

FIGURE 5.

Characteristic grid anode voltage curves for the ETA gun with 10-inch cathode and $22.3 \mathrm{~cm}$ anode position. The results of a previous calculation $(8 / 22 / 79)$ and the new improved calculations $(3 / 26 / 82)$ are shown. These curves represent the threshold for virtual cathode formation in the grid-anode space. The dashed curve is the decelerative threshold. 


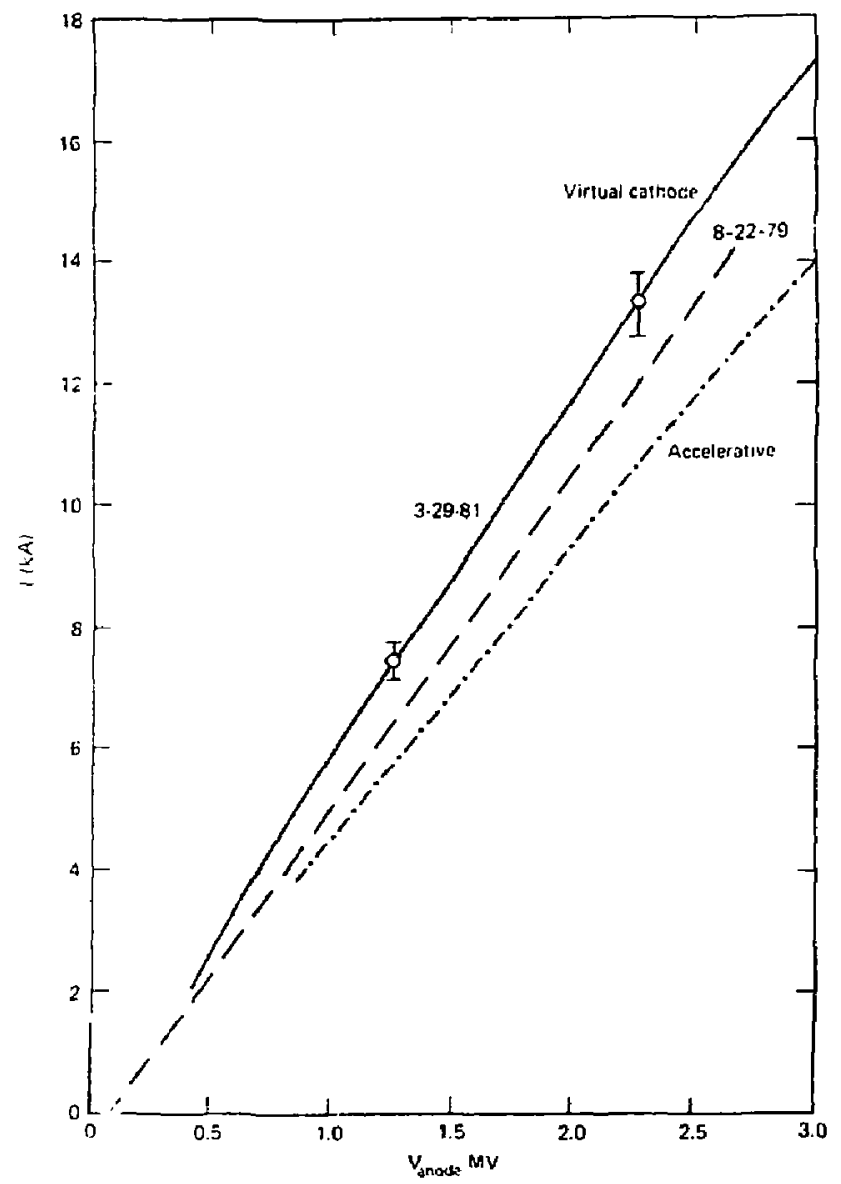

FIGURE 6.

Characteristic beam current anode voltage curves for the ETA gun showing the results of a previous calculation $(8 / 22 / 79)$ and the new improved calculations $(3 / 26 / 81)$. These curves represent the threshold for virtual cathode formation in the grid-anode space. The dashed curve is the decelerative threshold and is at $80 \%$ of the virtual cathode threshold current. 


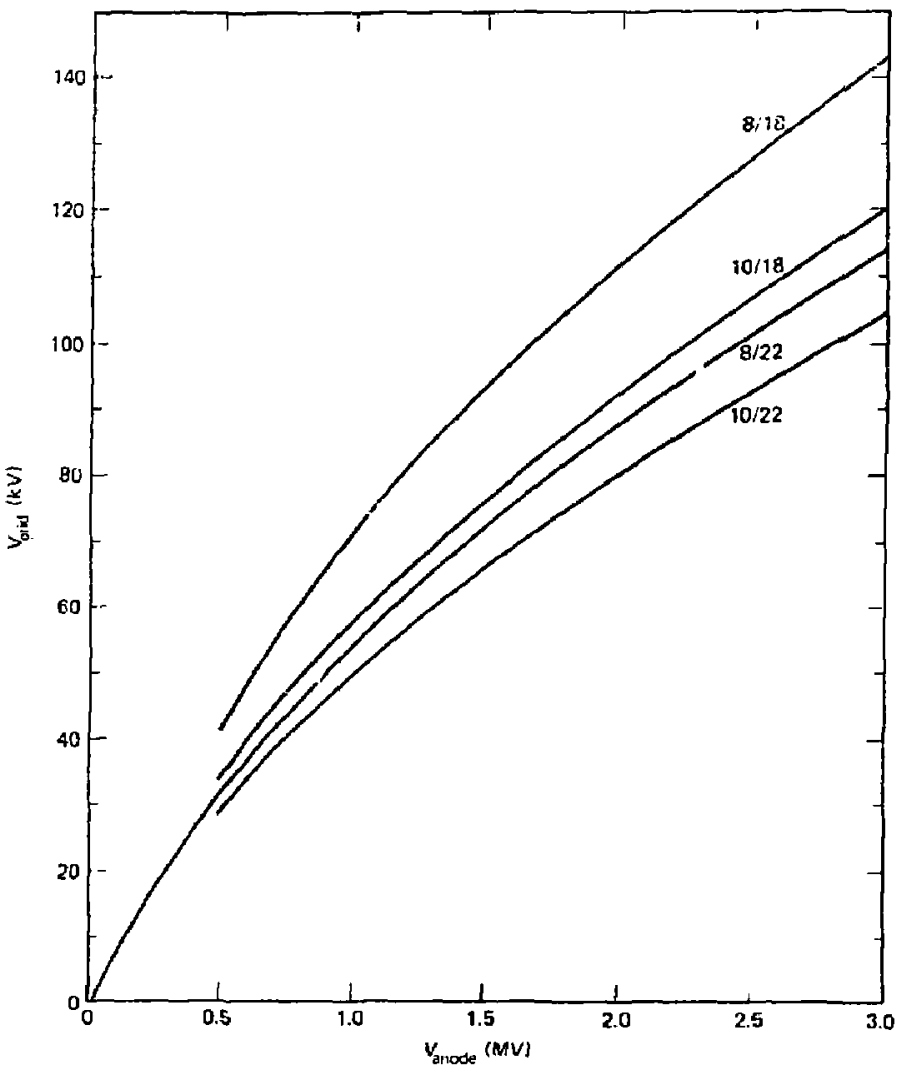

FIGURE 7.

Characteristic virtual cathode thiesholo grid anode voltage curves for the four geometries shown in Fig. 1. These geometries are labeled as the cathode diameter (inches) slash the anode position (cm). 


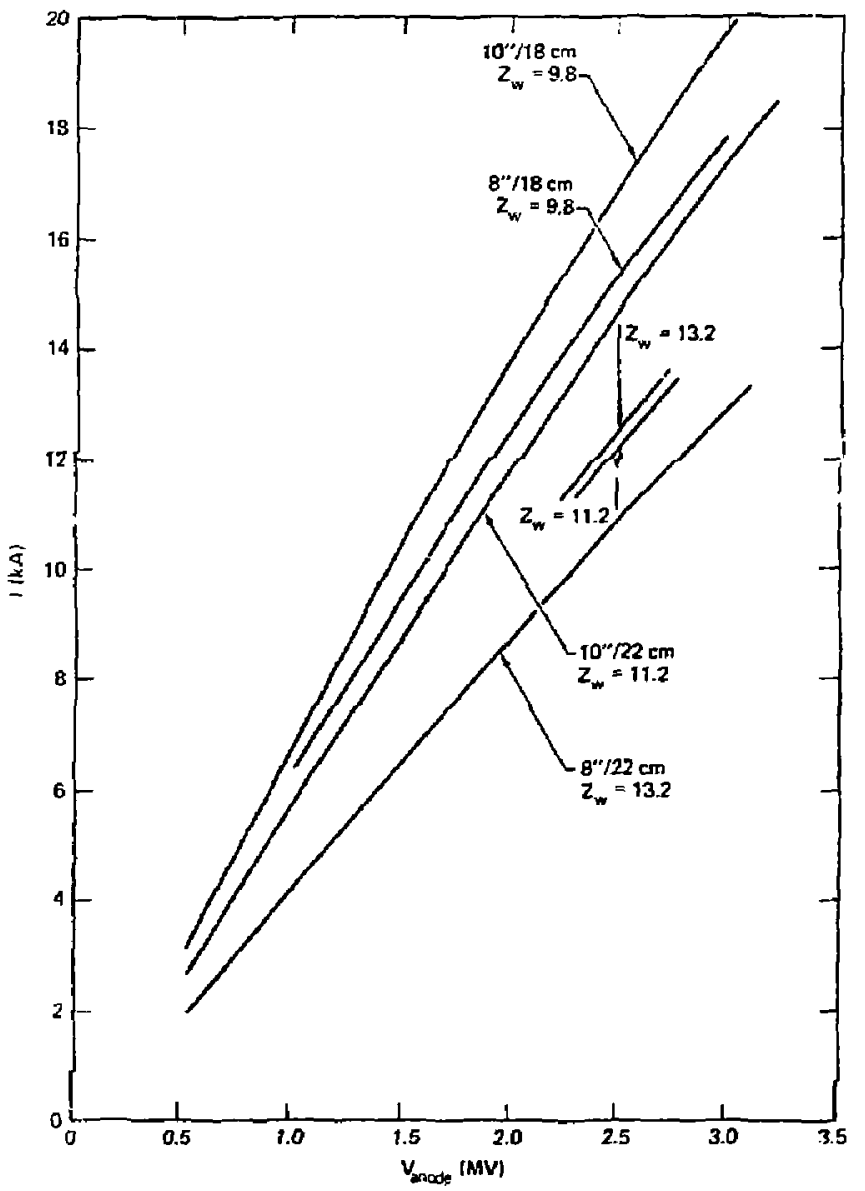

FIGURE 8.

Characteristic virtual cathode threshold beam current anode voltage curves for the four geometries shown in $F$ ig. 1. The effect on virtual cathode threshold by changes in the washer position as jndicated for the 10-inch/22 cm and $8-i n c h / 22 \mathrm{~cm}$ guns. 
$2.5 \mathrm{MV} 86 \mathrm{kV} 13.151 \mathrm{kA}=0$

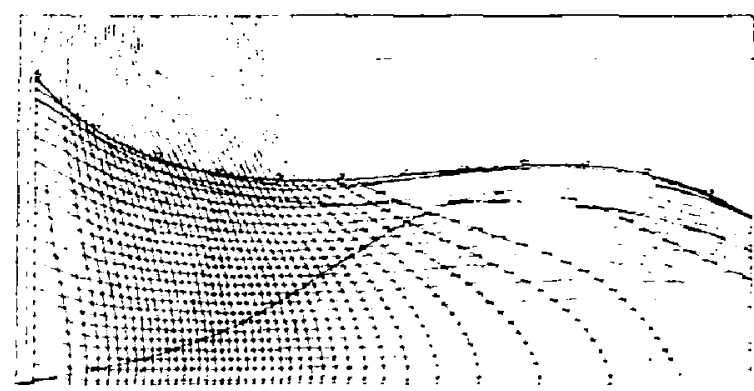

$2.5 \mathrm{MV} 92 \mathrm{kV} 14.479 \mathrm{kA}=-\because=-$
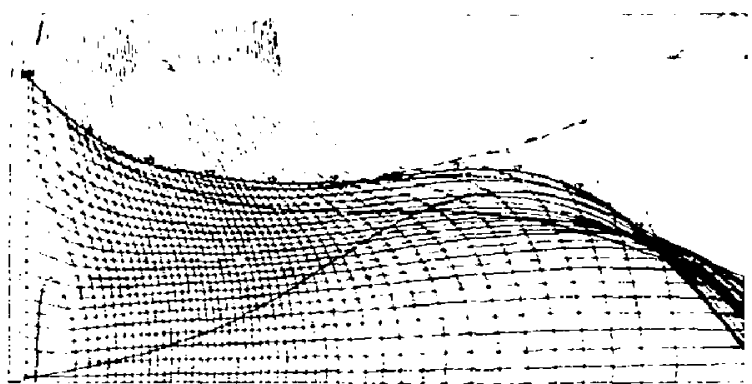

$2.5 \mathrm{MV} 93 \mathrm{kV} 14.76 \mathrm{BA}=\ldots$ - $=$ -

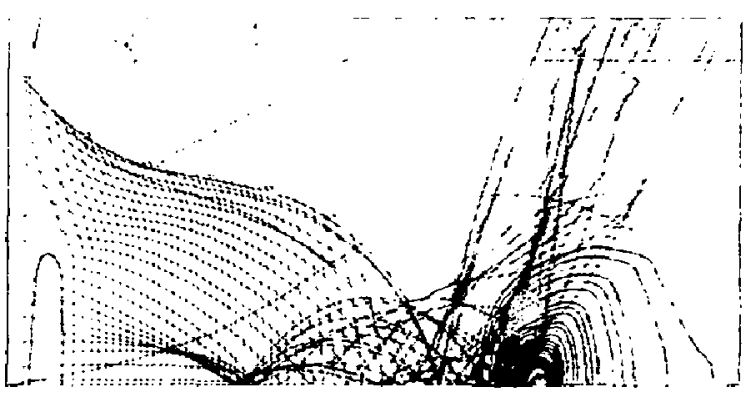

Just inside

decelerative regime.
Just below virtual cathode formâ..un.
Just above virtual cathode formation.

FIGURE 9 .

2.5 MVETA configuration with $12.7 \mathrm{~cm}$ radius washer at $11.2 \mathrm{~cm}$. Rurns are at 86, $9 \mathrm{c}$ and $93 \mathrm{kV}$ on the grid. 


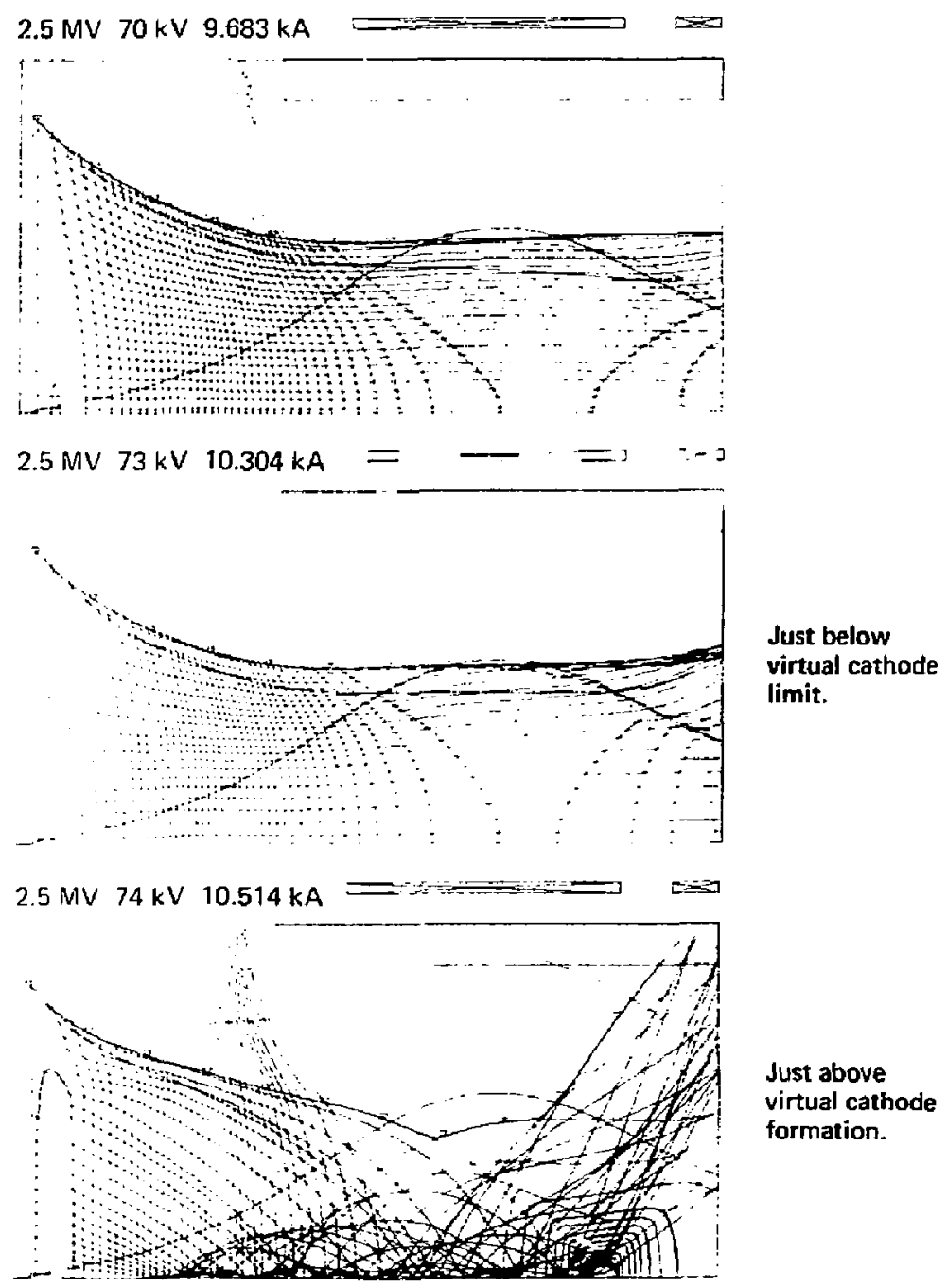

FIGURE 10.

Z. FV ETA configuration of $F$ ig. I without the washer. Runs are at 70,73 and $7 \dot{4}, y$ on the grid. 

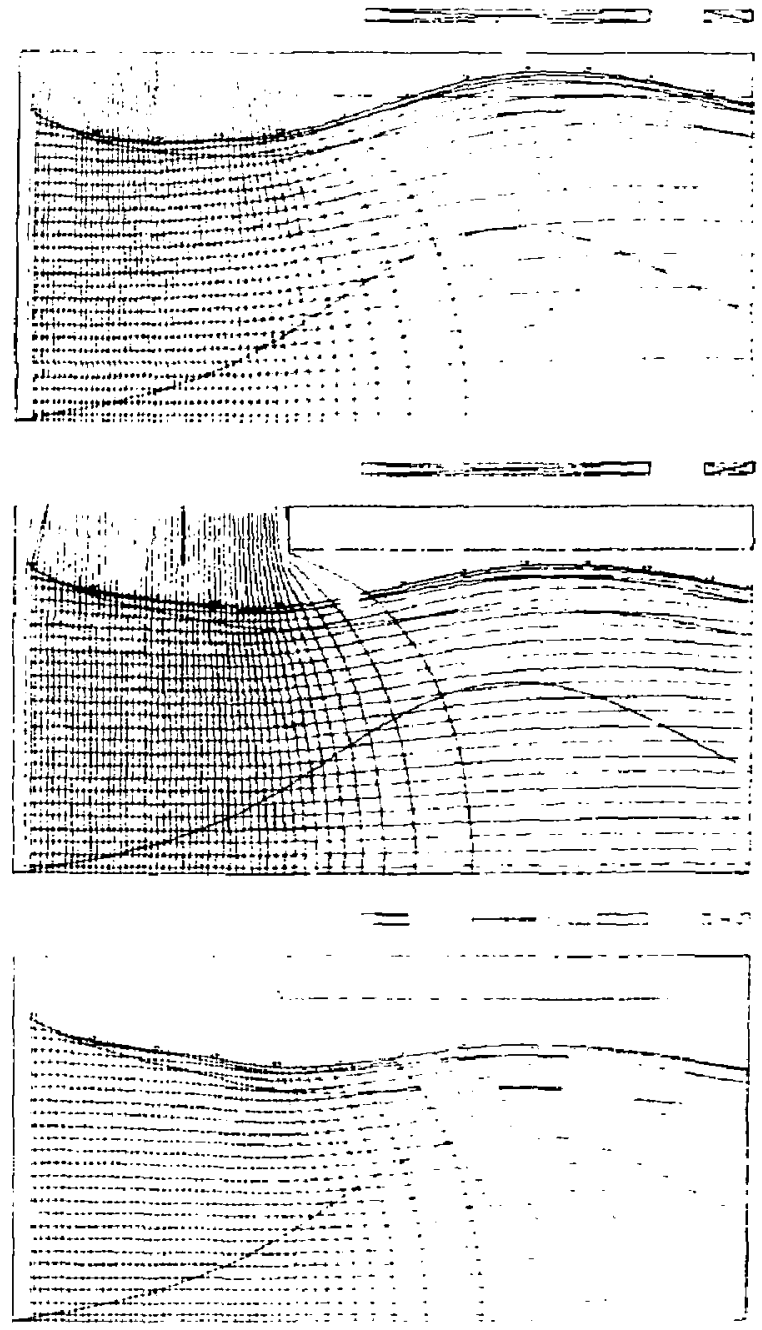

FIGURE 11.

1 ampere 2.5 MV anode ETA gun a) washer centered, b) washer 1-inch toward anode, c) washer 2 -inches toward annde. 


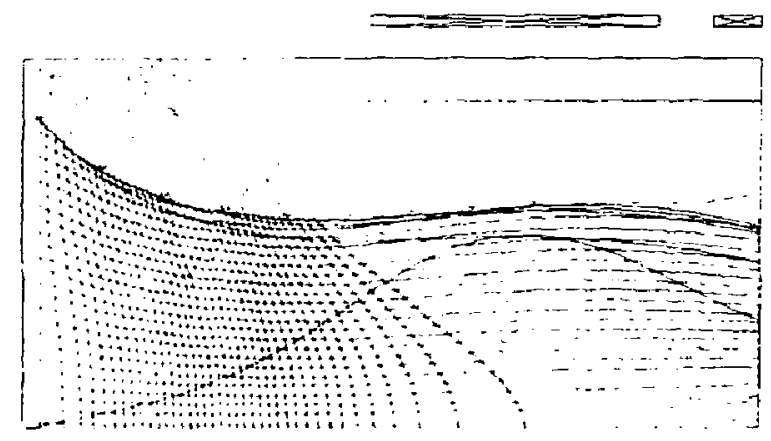

$118 \mathrm{kA}$ beam in accelerature regime.

Washer centered

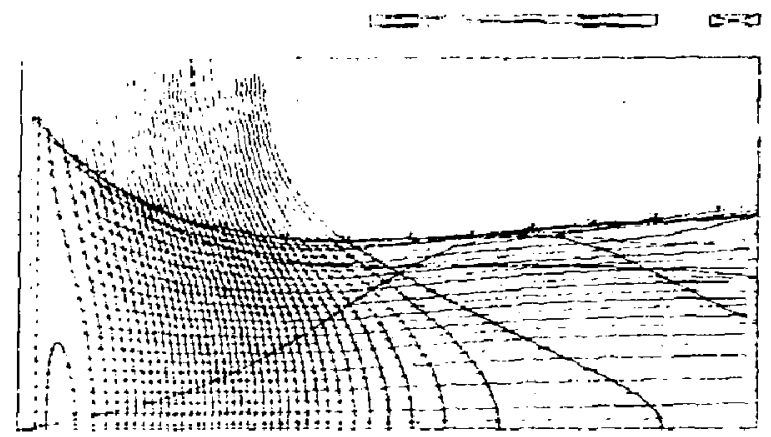

$11.8 \mathrm{kA}$ beam

below virtual cathode limit.

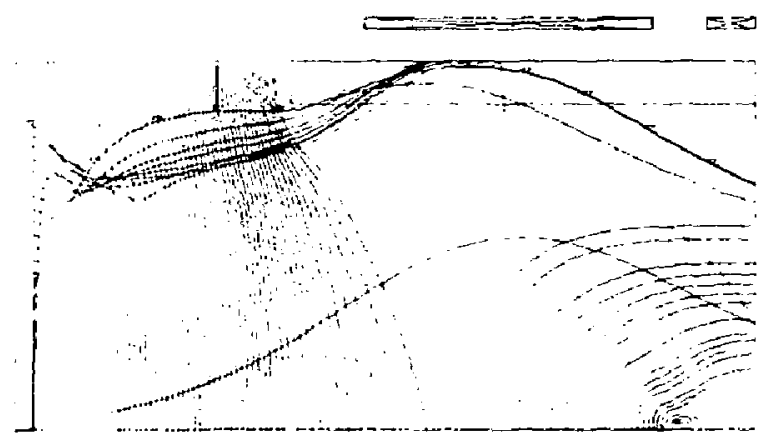

$11.8 \mathrm{kA}$ beam above virtual cathode limit.

FIGURE 12.

$17.8 \mathrm{k}$ amp $2.5 \mathrm{MV}$ anode ETA gun a) washer centereo, b) washer 1 -inch toward anode, c) washer 2-inches toward anode. 
$2.5 \mathrm{MV} 85 \mathrm{kV} 12.929 \mathrm{kA}$
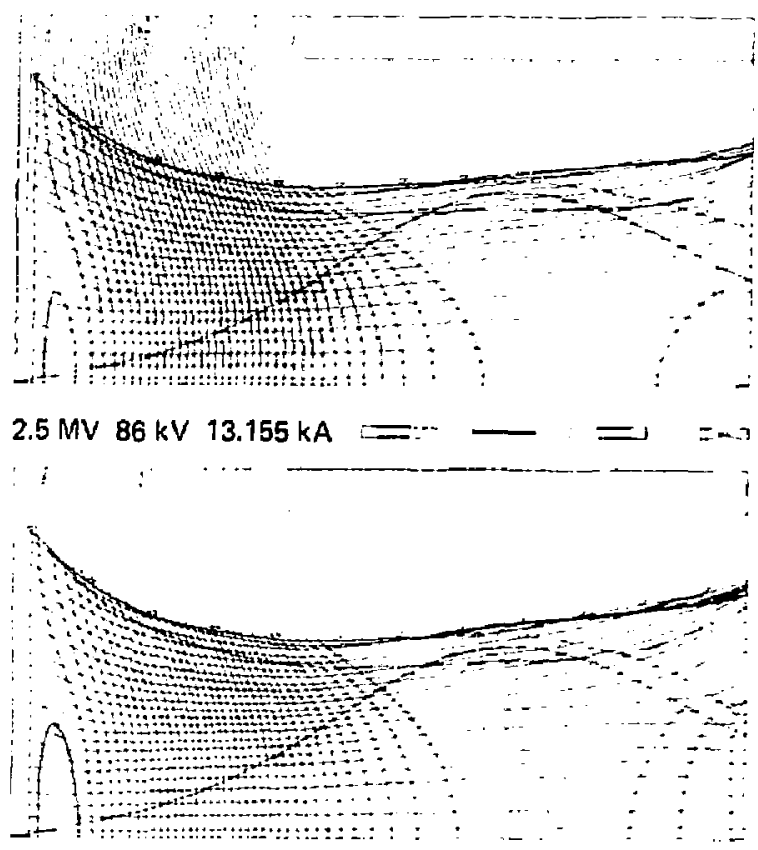

$2.5 \mathrm{MV} 37 \mathrm{kV} 13.382 \mathrm{kA}=-$

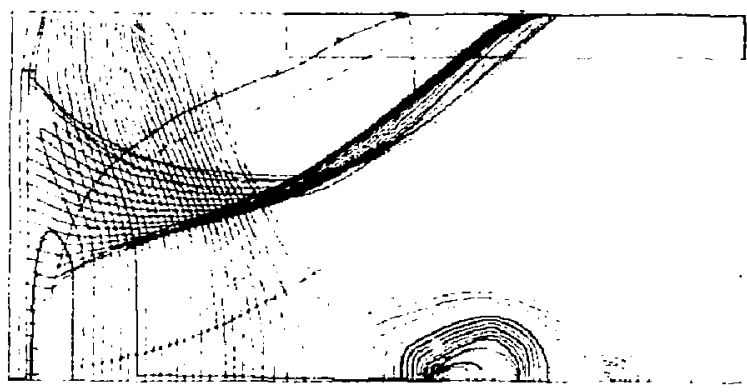

FIGURE 13.

2.5 MVETA conf iguration with $14.5 \mathrm{~cm}$ washer at $z=11.2 \mathrm{~cm}$. Runs are for 85 , 86 , and $87 \mathrm{kV}$ on the grid. 


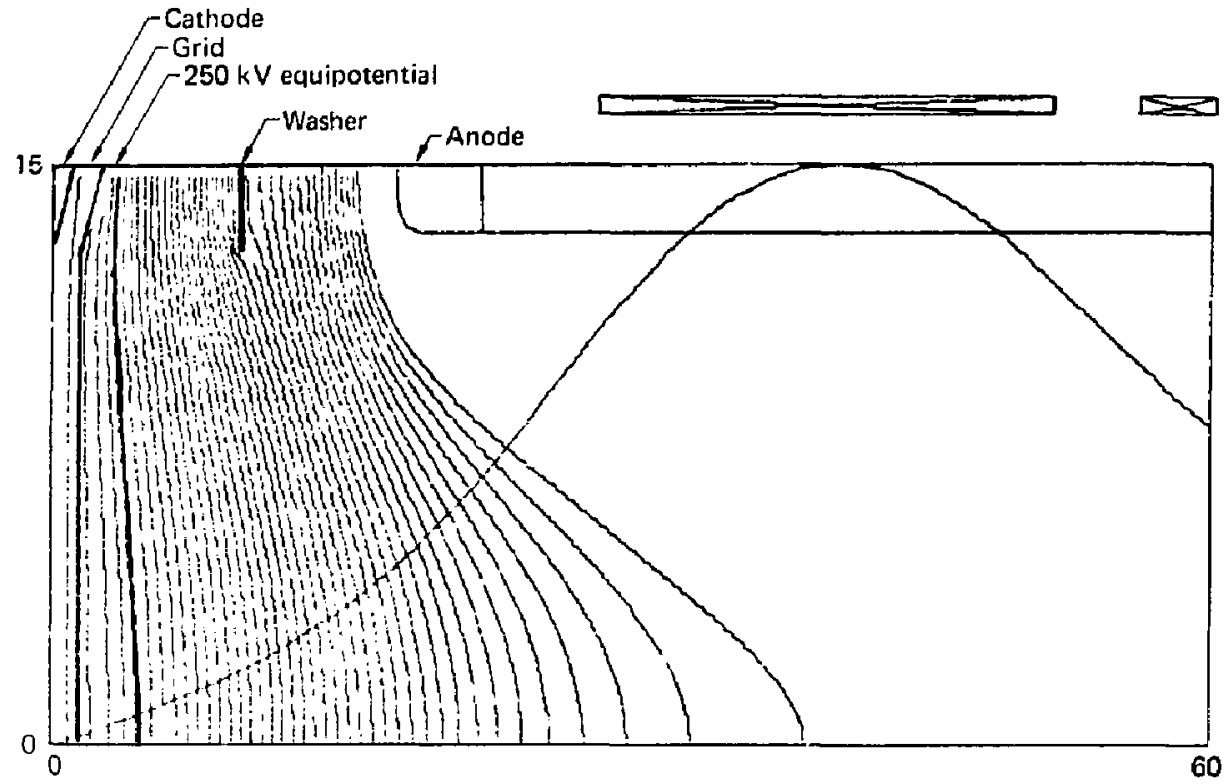

FJGURE 14.

The equipotential surfaces in the ETA geometry in the presence of the charge resulting from the passage of $11 \mathrm{kA}$ beam. The anode potential was $2.5 \mathrm{MV}$ ano the grid is at $80 \mathrm{kV}$. The $250 \mathrm{kV}$ equipotential is inaicated for use as a boundary condition in the expansion of the first few $\mathrm{cm}$ of the gun. 


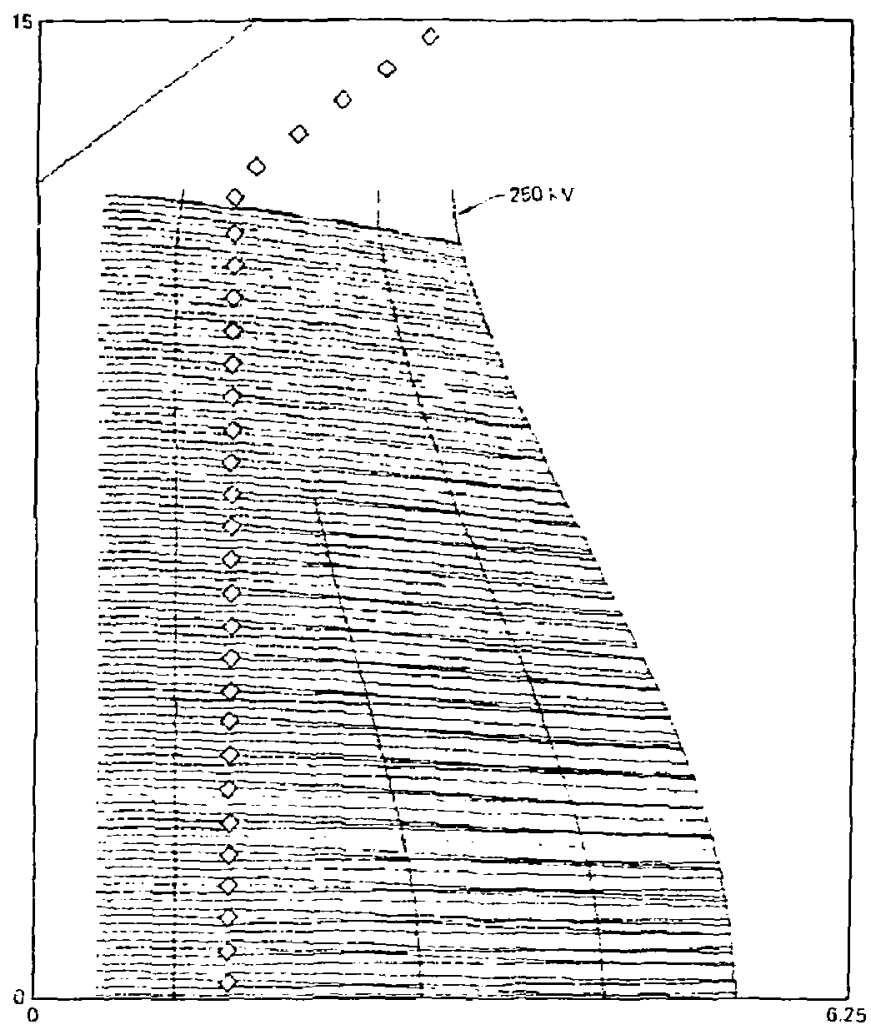

FIGURE 15.

The expanded cathode $250 \mathrm{kV}$ boundary region showing the grid simulated by concentric wire rings spaced every ha if $\mathrm{cm}$. The focusing of the electron beam infintesimal in diameter and wires is evident. The grid wires are diamonds centered at the wire location. 


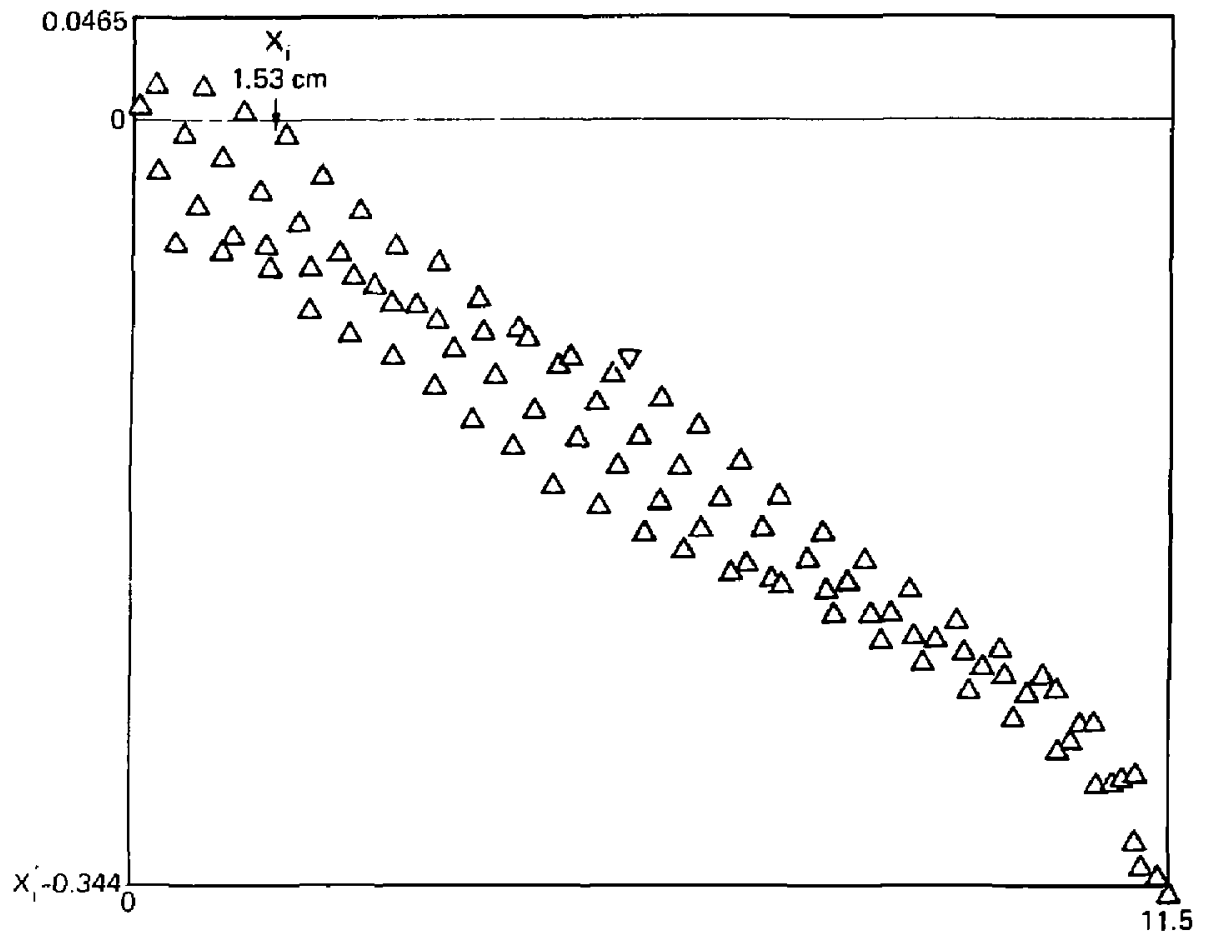

FIGURE 16.

The beam phase space at the $250 \mathrm{kV}$ equipotential surface showing the filementation introduced by the lens action of the grid wires spaced on half $\mathrm{cm}$ intervals. The normalized beam emittance is $580 \mathrm{~cm}-\mathrm{mr}$. 

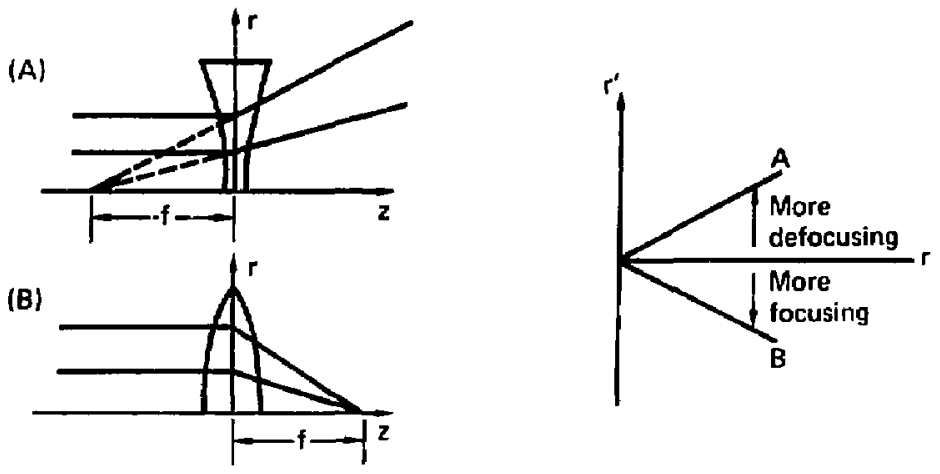

\section{FIGURE 17.}

Ideat lens, A diverging and B converging. The angular slope is proportional to the radial position inside the lens and results in a linear phase plot as shown.

(A)

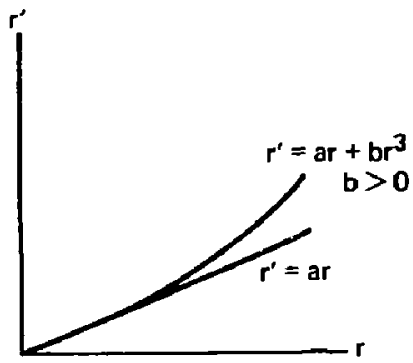

FIGURE 18.

(B)

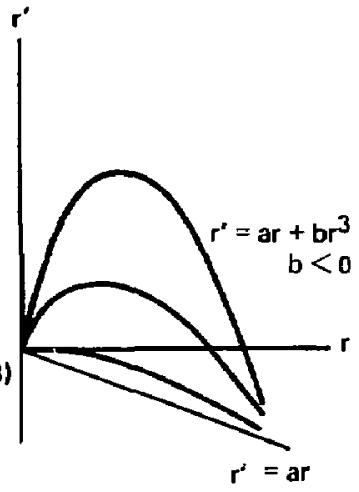

Real lenses are stronger at their perimeter and contribute a cubic spherical nonlinearity to the phase plase A). Approach to the virtual cathode limit results in the defocusing of the inner portion of the beam $B)$ and results in $a$ cubic nonlinearity of the opposite sign to that of spherical aberration. 

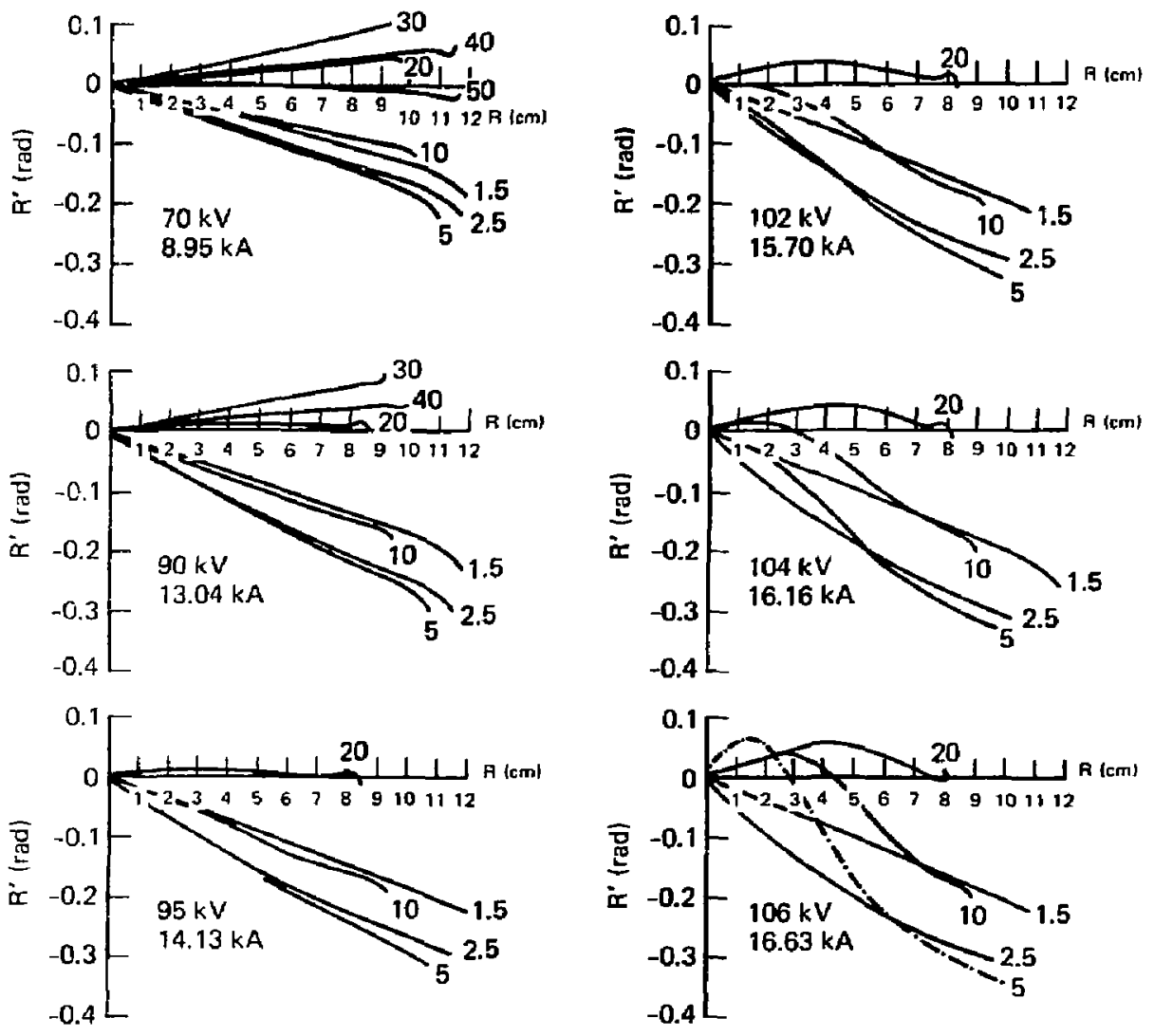

FIGURE 19.

2.5 MV anode, 10 -inch/18 cm ETA phase space for the various grid potentials indicated. The different curves within each frame are the $x-x$ phase space projections at the indicated longitudinal positions. 


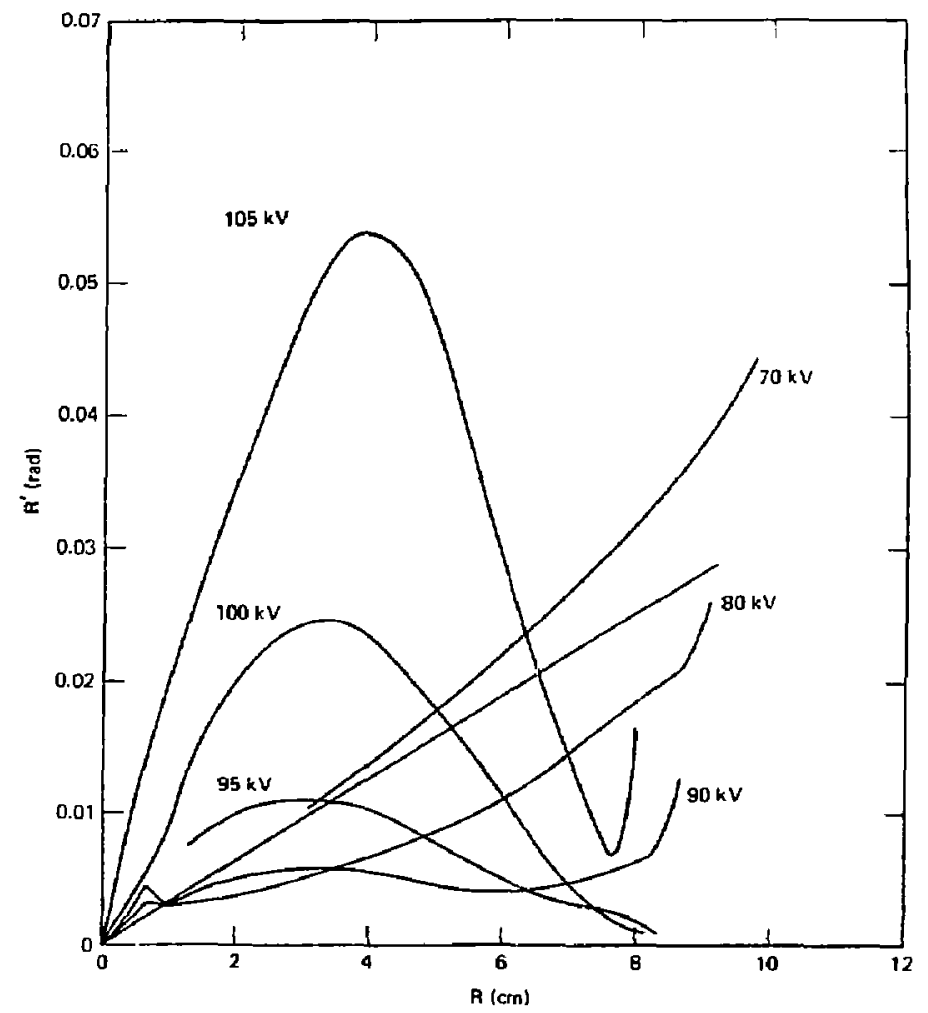

FIGURE 20.

2.5 MV anode 10 -inch $/ 18 \mathrm{~cm}$ ETA phase space frame at longitudinal position of $20 \mathrm{~cm}$. This is just insicie the anode entrance. Note the increase slope at large $r$ value for the $70 \mathrm{kV}$ curve relative to the linear extrapolation from the slope at small $r$. This is the result of the anode spherical aberration. At the higher grid voltages (higher beam currents) the phase space is bowed by the beam coherent effects close to the virtual cathode formation. 


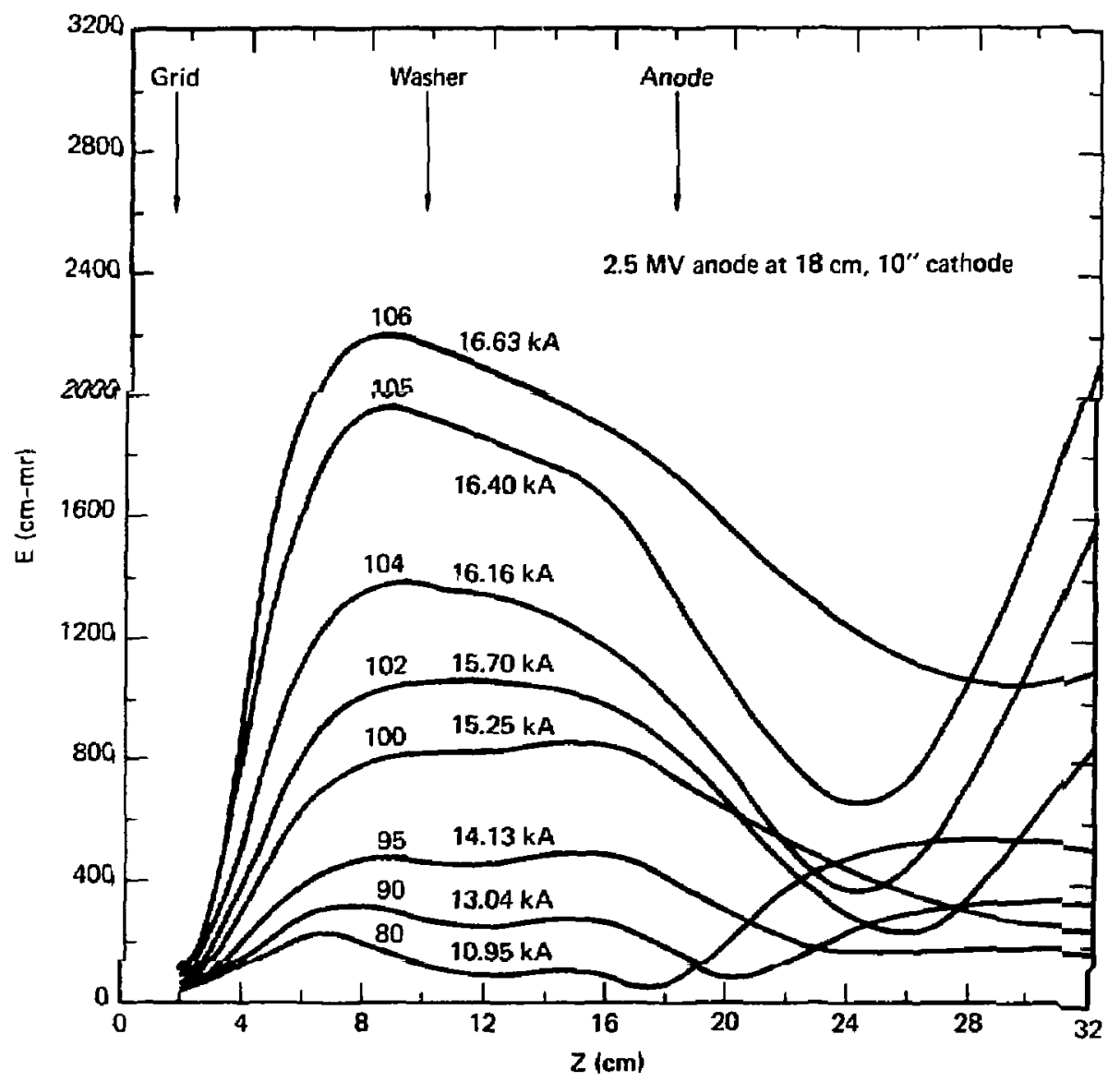

FIGURE 21.

Normalize beam emittance for the $2.5 \mathrm{MV}$ anode $10-i n c h / 18 \mathrm{~cm}$ ETA gun along the first $32 \mathrm{~cm}$ of the gun for various grid potentials and their associated beam currents. At smali currents the emittance grows after entry into the anode as a result of spherical aberration. At current just below virtual cathode formation the enittance is spoiled by the coherent effects just past the grid. At intermediate currents, the emittance is best from partial concellation of the coherent growth and the anode spherical aberration. Note particulariy the $95 \mathrm{kV}$ operation. 


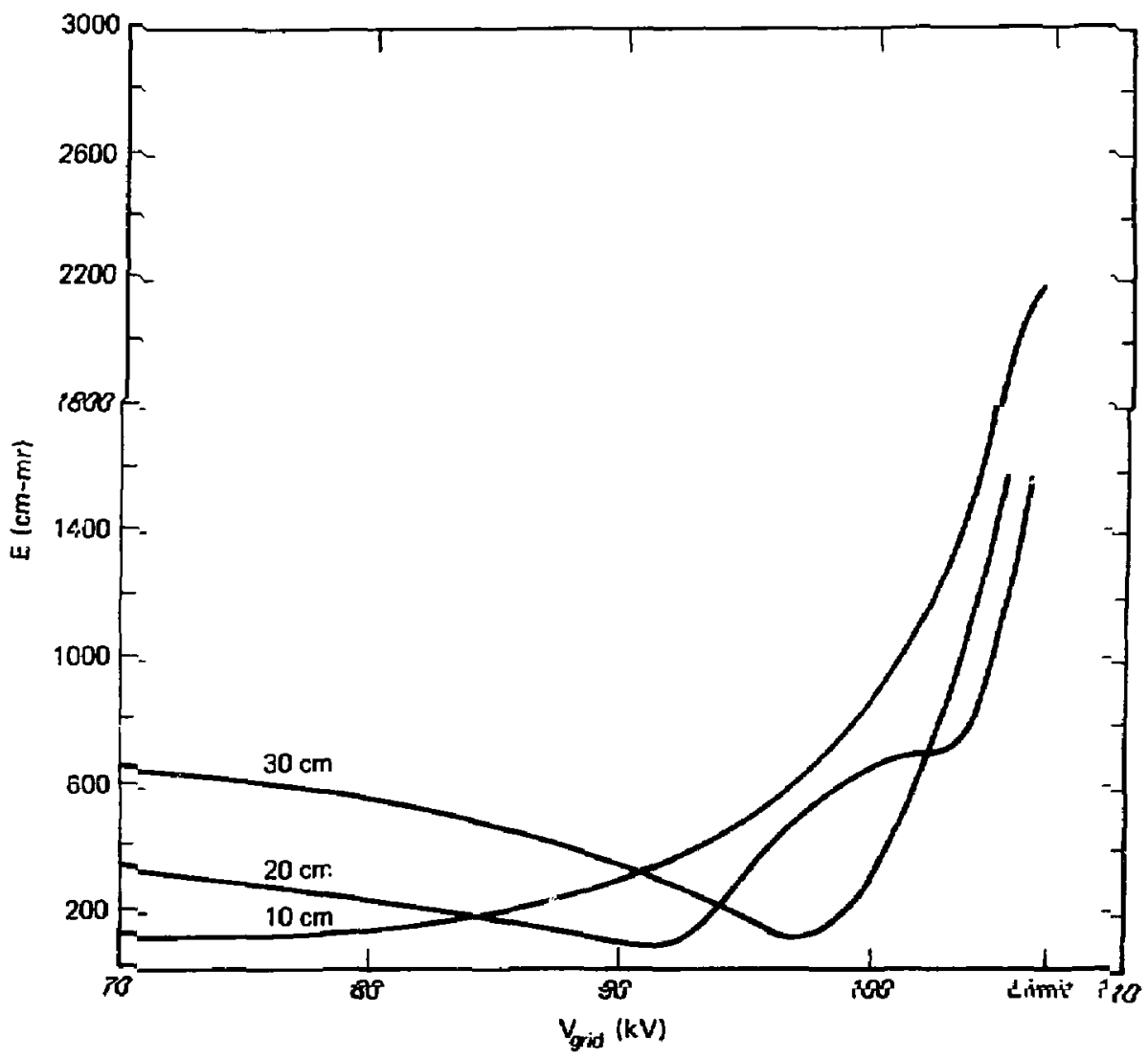

FIGURE 22.

The normalized emittance of Fig. 21 plotted against grid potential at 10,20 and $30 \mathrm{~cm}$ logitudinal positions. The minimum reached at $95 \mathrm{kV}$ results from the partial concellation of the coherent growth and anode spherical aberration. The virtual cathode threshold is at $107 \mathrm{kV}$. Note the large emittance growth as this limit is approached. 


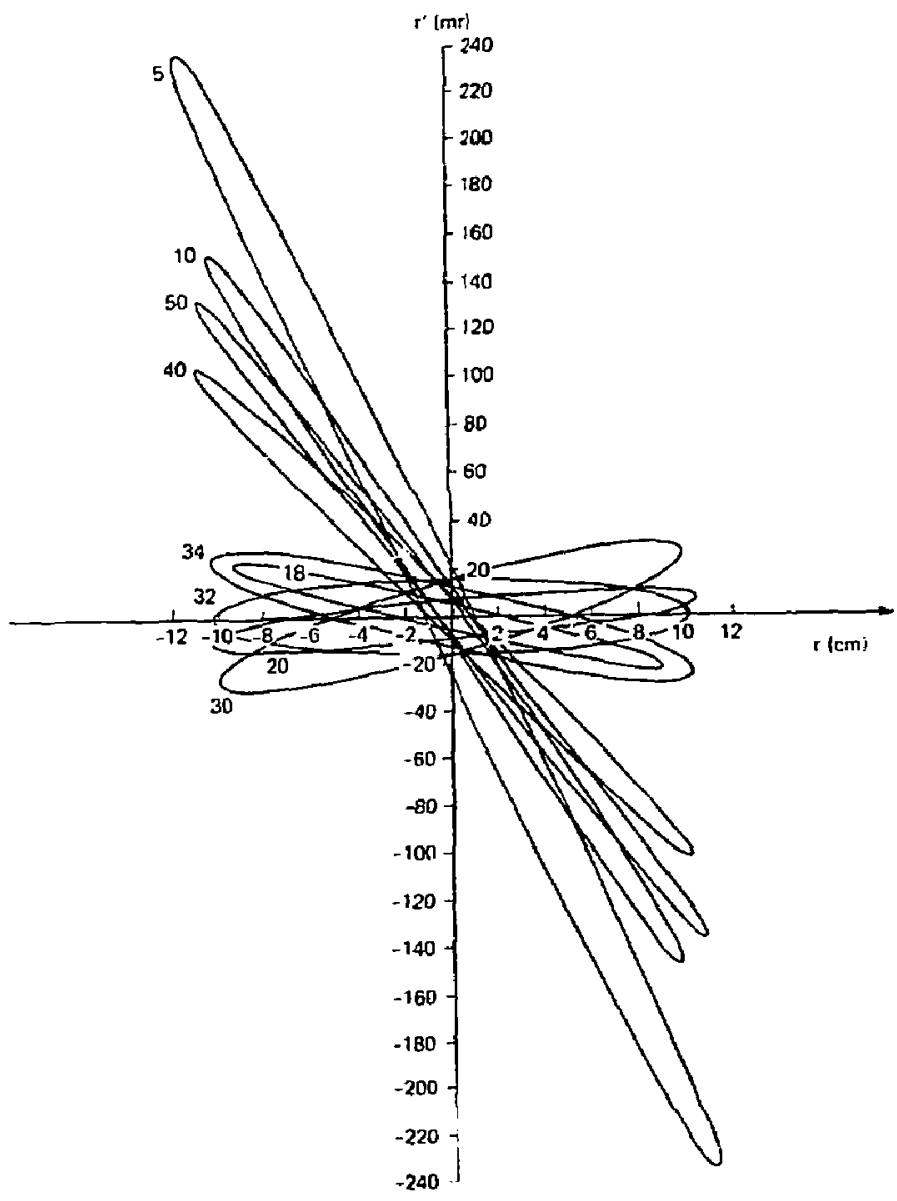

FIGURE 23.

$2.5 \mathrm{MV}$ anode, $80 \mathrm{kV}$ ETA 10 -inch/18 cn geometry prase space. The circumscribed ellipses about phase points are shown for the indicated longitudinal positions. These eijipses $c$ an be used for match into transport runs. Note the waist at 19 and $32 \mathrm{~cm}$, bracketting the catcher coil position. 


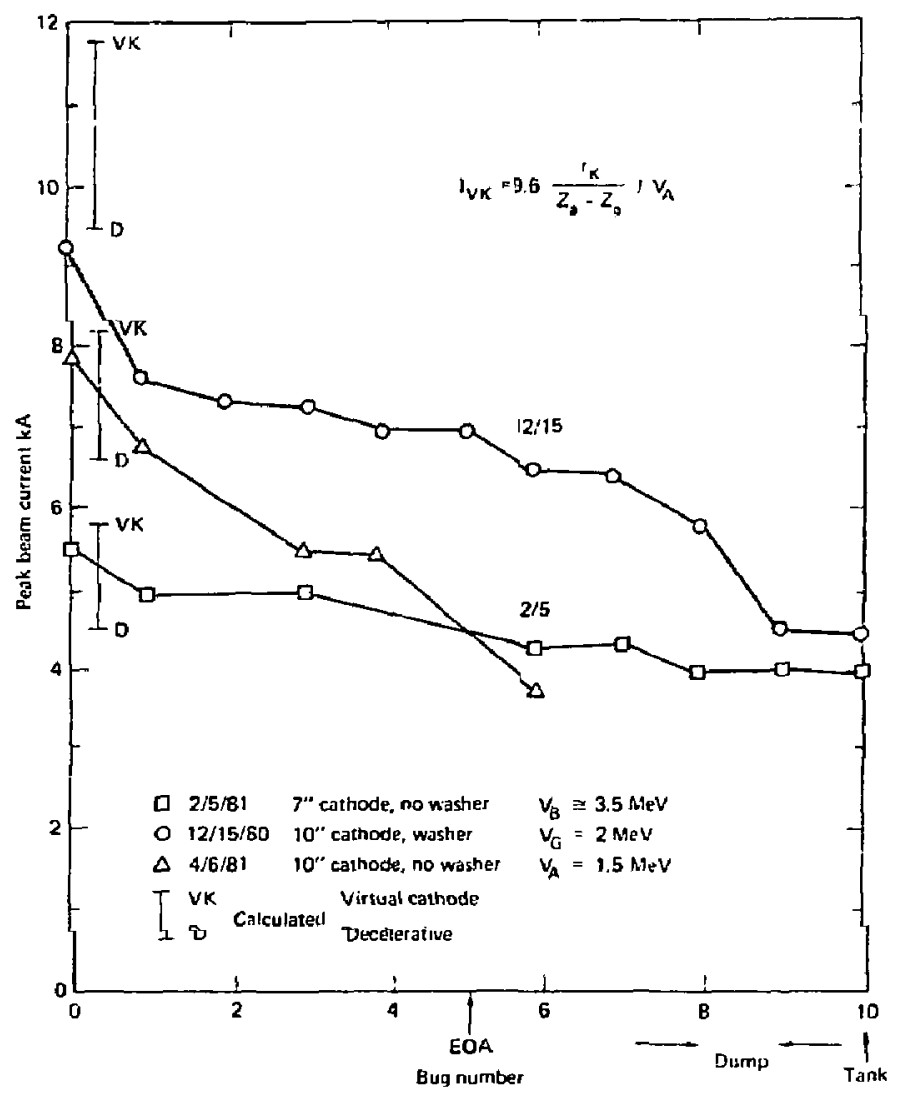

FIGURE ?4.

Comparison of calculated deceleration and virtual cathode thresholds and ETA operation for three different operating geometries. The theoretical points are derived from $\mathrm{Eq} .11$ and presented in Table 5. 
Beam profiles for the four geometries of $\mathrm{Fig.} 1$ are presented in the following four figures. Each figure consists of a set of three profiles for each of six anode potentials of $0.5,2.0,1.5,2.0,2.5$ and $3.0 \mathrm{MV}$. The set of three profiles at each anode potential are for different grid voltages, the first being well below the virtual cathode threshold, the second just below the virtual cathode threshold, and the third just above the virtual cathode threshold. In these figures the boxes with the crosses are the cross sections of the focusing coils and the bell shaped curve passing through the origin, rusing to a peak at the first coil is the plot of the axial external focusing magnetic field. Electron trajectories are basically the horizontal lines and the equipotentials are basically the vertical lines on these plots. The dashed line visible in some of the plots is the beam envelope on the previous iteratirn and indicates the degree of convergence of the solution.

ANODE (NY)

\section{5}

1.0

1.5

2.0

2.5

3.0

0.1

0.25

\section{0-in/22 cm} FIGURE 25

$A$
$B$
$C$
$D$
$E$
$F$

\section{8- in $/ 18 \mathrm{~cm}$} F]GURE 26

$A$
$B$
$C$
$D$
$E$
$F$

\section{8-in/ $22 \mathrm{~cm}$} F IGURE 27

$\begin{array}{ll}\text { A } & \text { A } \\ B & \text { B } \\ \text { C } & \text { C } \\ \text { D } & \text { D } \\ \text { E } & \text { E } \\ \text { F } & \text { F } \\ \text { G } & \\ \text { H } & \end{array}$

The data for $E B Q$ from which these runs we made is given in Table 6 . 
$0.5 \mathrm{MV} 25 \mathrm{kV}$

\section{$2.086 \mathrm{kA}$}

1.

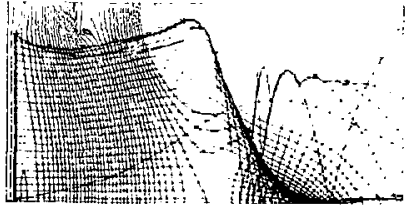

\section{$0.5 \mathrm{MV} 28 \mathrm{kV}$}

$2.469 \mathrm{kA}$

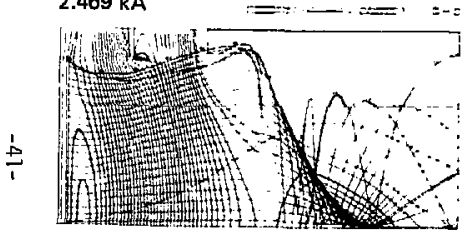

$0.5 \mathrm{MV} 29 \mathrm{kV}$

$2.602 \mathrm{kA}$

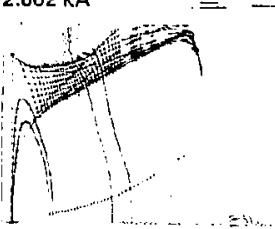

$1.0 \mathrm{MV} 44 \mathrm{kV}$

$4.848 \mathrm{kA}$

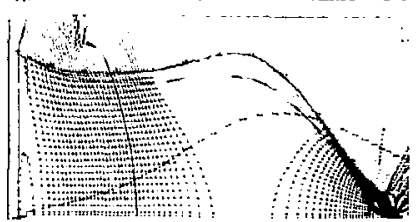

1.0 MV $49 \mathrm{kV}$
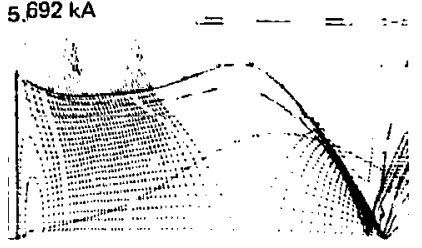

$1.0 \mathrm{MV} 50 \mathrm{kV}$

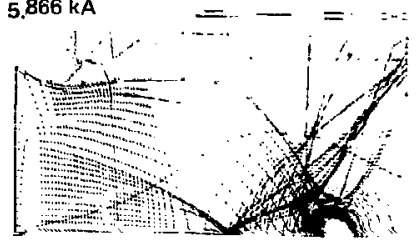

$1.5 \mathrm{MV} 60 \mathrm{kV}$

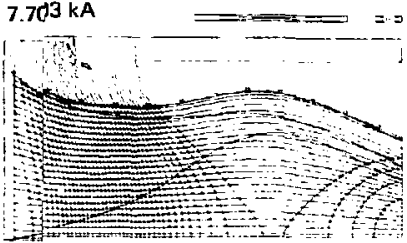

$1.5 \mathrm{MV} 65 \mathrm{kV}$
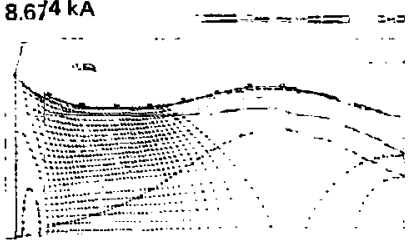

\section{$1.5 \mathrm{MV} 66 \mathrm{kV}$}

$8.873 \mathrm{kA}$

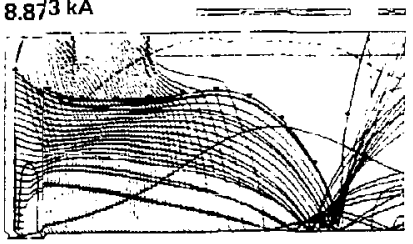

FIGURE $25 \mathrm{~A}$, B \& C. Standard ETA gun geometry. Ten inch cathode with 22.4 cm anode cathode separation. Washer is at $11.2 \mathrm{~cm}$. 

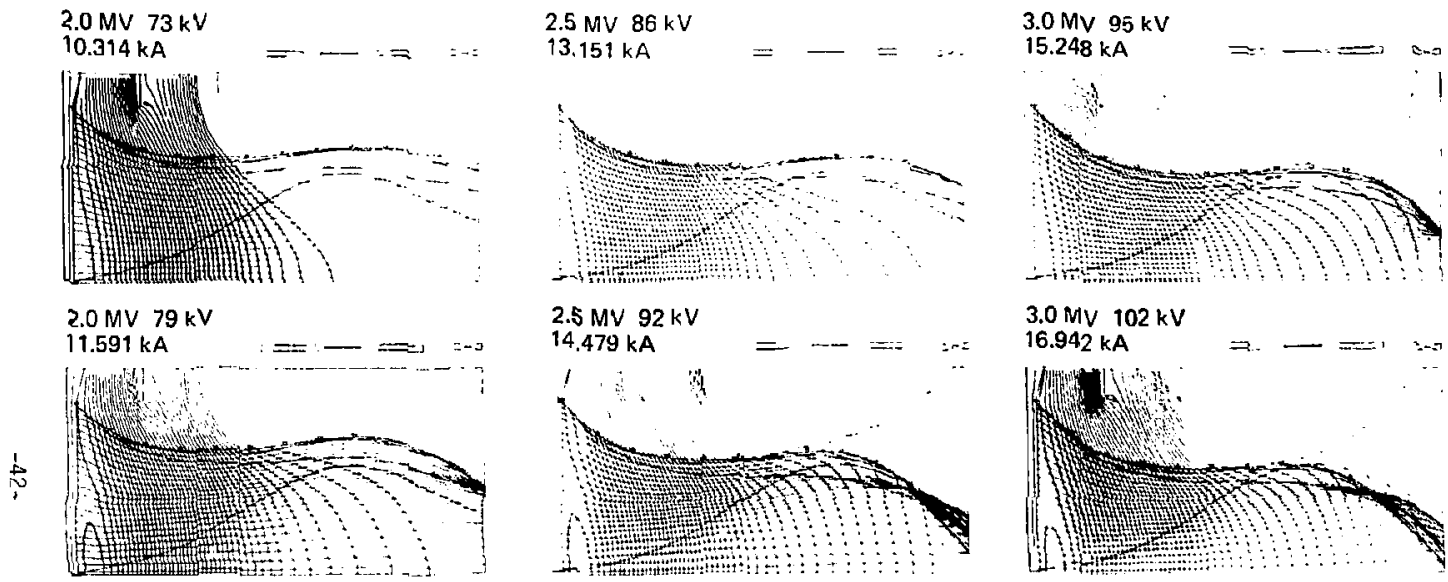

$3.0 \mathrm{MV} 102 \mathrm{kV}$

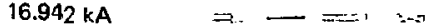

\section{$2.0 \mathrm{MV} 80 \mathrm{kV}$}

$11.809 \mathrm{kA}=$

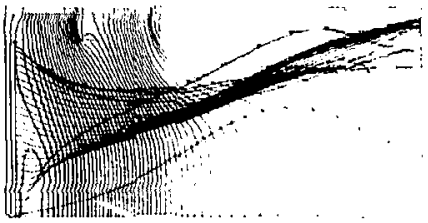

\section{$2.5 \mathrm{MV} 93 \mathrm{k}:$}

$14.768 \mathrm{kA}$
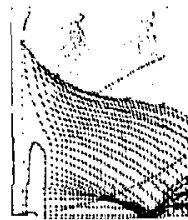

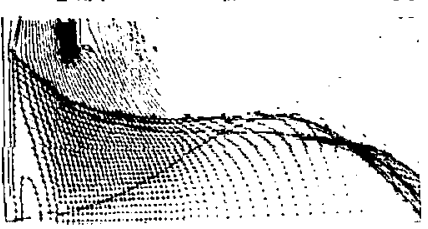

\section{$3.0 \mathrm{MV} 104 \mathrm{kV}$}

$17.436 \mathrm{kA}$

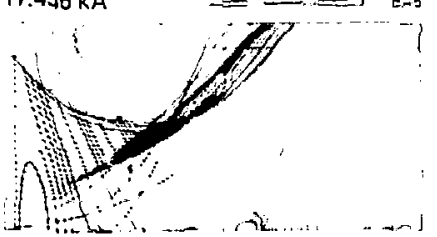

FIGURE $25 \mathrm{D}, \mathrm{E} \& \mathrm{~F}$. Standard ETA gun geometry. Ten inch cathode with $22.4 \mathrm{~cm}$ anode cathode separation. Washer is at $11.2 \mathrm{~cm}$. 


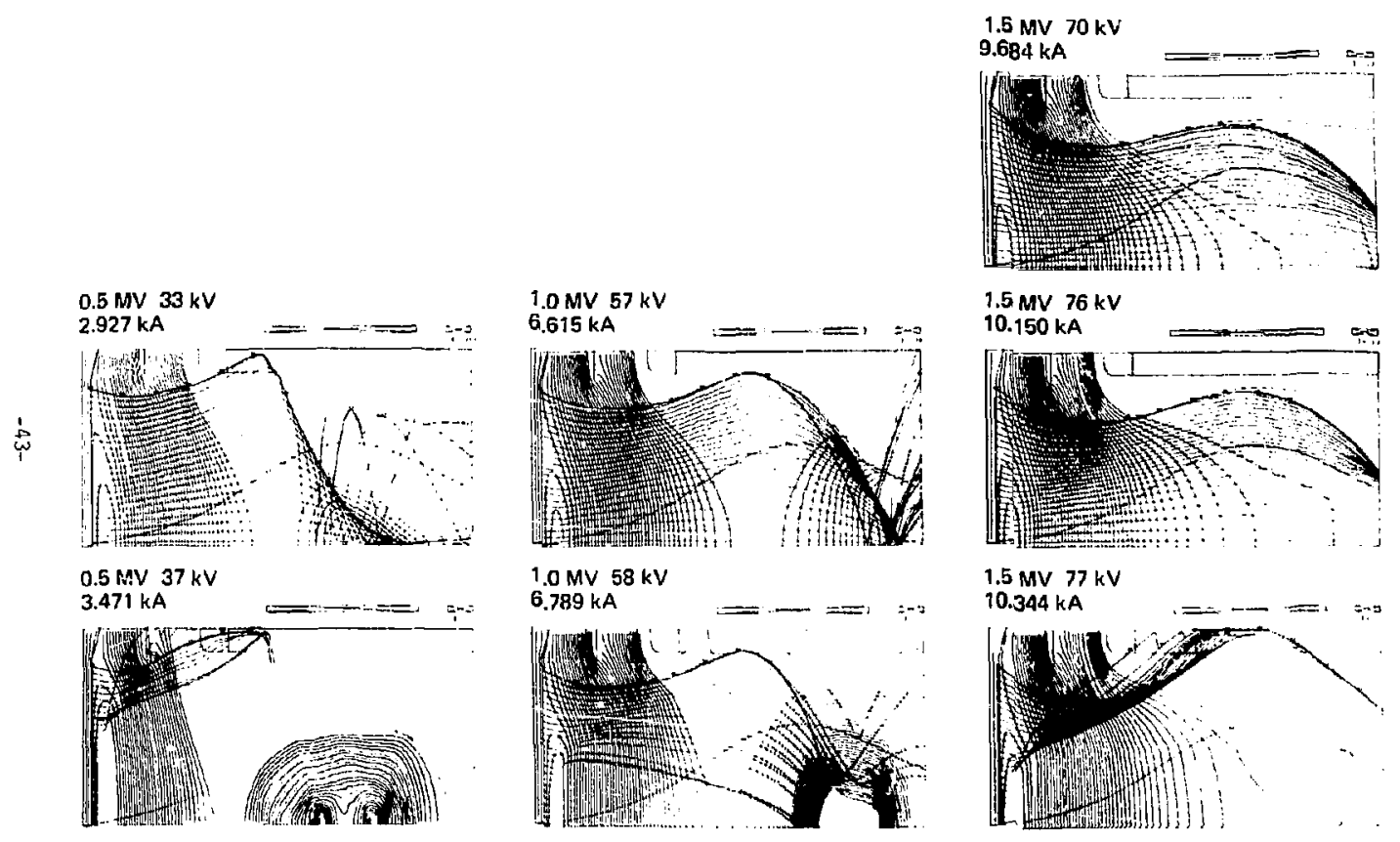

FIGURE $26 \mathrm{~A}, \mathrm{~B} \& \mathrm{C}$. Ten inch cathode gun with $18 \mathrm{~cm}$ anode cathode separation. Washer is at $9.8 \mathrm{~cm}$. 
Figurs 260
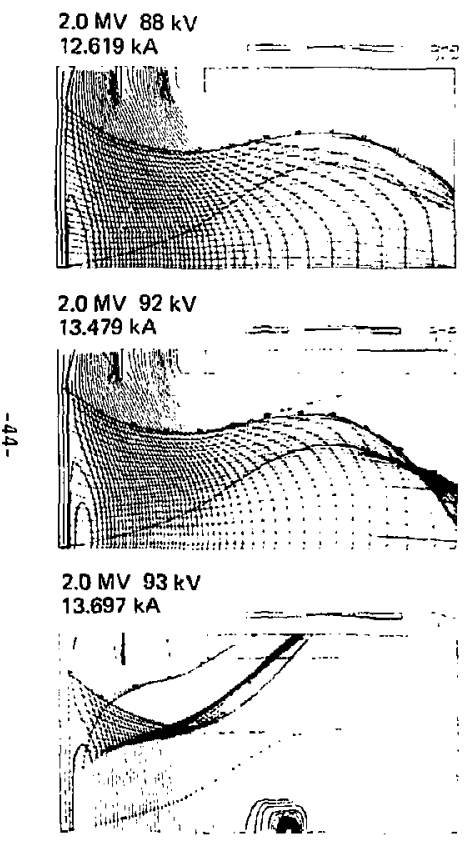
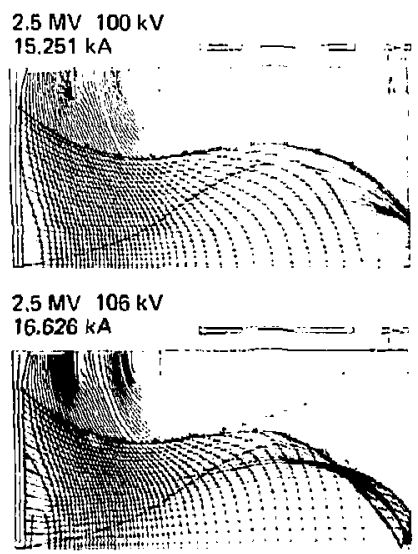

$2.5 \mathrm{MV} 107 \mathrm{kV}$

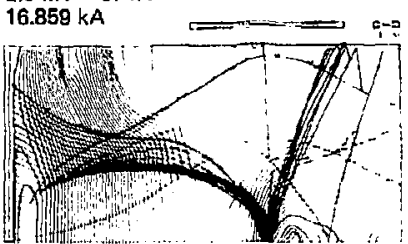

Figure $26 \mathrm{~F}$
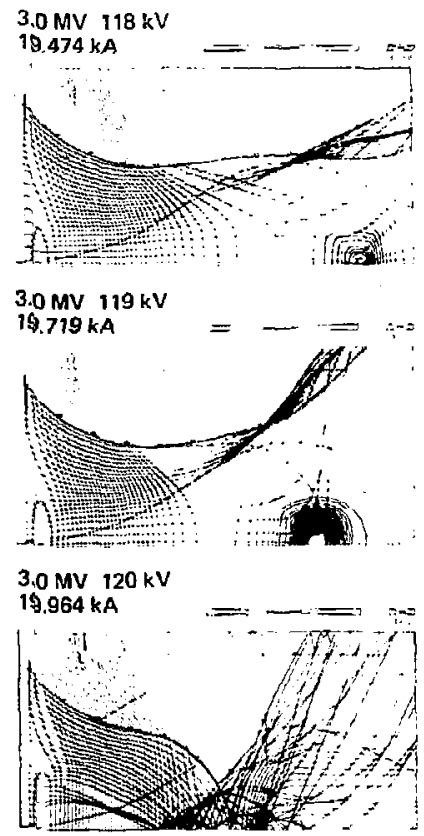

FIGURE $26 \mathrm{D}, \mathrm{E} \& \mathrm{~F}$. Ten inch cathode gun with $18 \mathrm{~cm}$ anode cathode separation. Washer is at $9.8 \mathrm{~cm}$. 
Figure $27 \mathrm{~A}$

0.5 MV 25 kV 1.342 kA

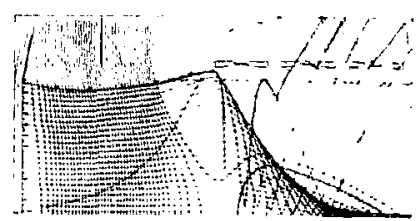

\section{$0.5 \mathrm{MV} 31 \mathrm{kV} 1.852 \mathrm{kA}$}

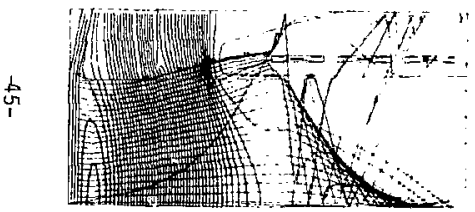

$0.5 \mathrm{MV} 32 \mathrm{kV} 1.942 \mathrm{kA}$

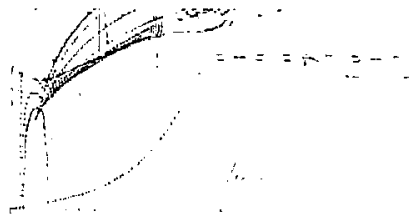

Fiqure $27 B$

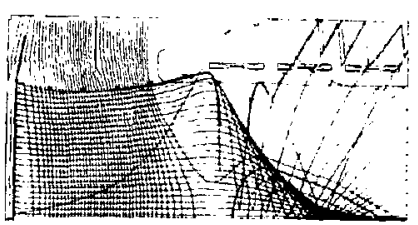

$1.0 \mathrm{MV} 54 \mathrm{kV} 4.242 \mathrm{kA}$

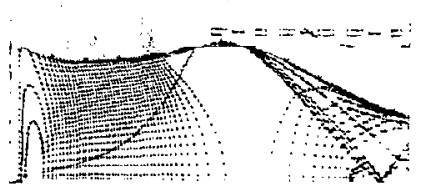

1. $0 \mathrm{MV} 55 \mathrm{kV} 4.359 \mathrm{~km}$

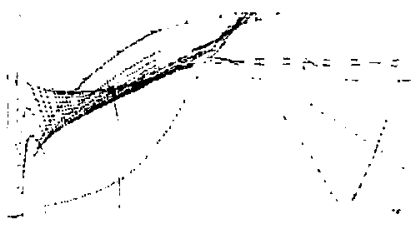

Figure $27 \mathrm{C}$

1.5MV $55 \mathrm{kV} 4.36 \mathrm{kA}$

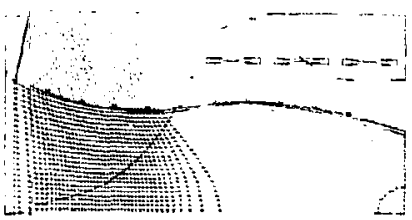

1.5 MV $73 \mathrm{kV} 6.644 \mathrm{kA}$

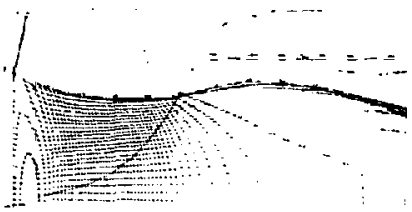

$1.5 \mathrm{MV} 74 \mathrm{kV}$

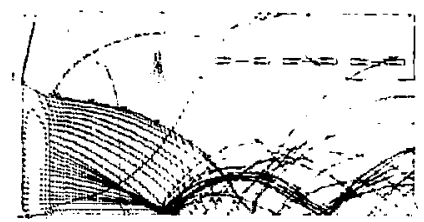

FIGURE $27 \mathrm{~A}, \mathrm{~B} \& \mathrm{C}$. Eight inch cathode gun. The anode is $22.4 \mathrm{~cm}$ from the catrode with the washer at $11.2 \mathrm{~cm}$. 
Figure $27 \mathrm{D}$

$2.0 \mathrm{MV} 80 \mathrm{kV} 7.612 \mathrm{kA}$

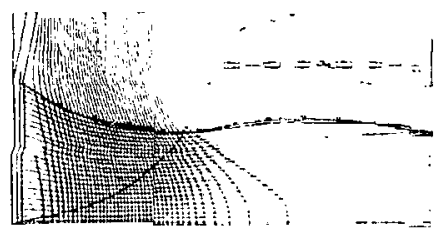

$2.0 \mathrm{MV} 87 \mathrm{kV} 8.622 \mathrm{kA}$

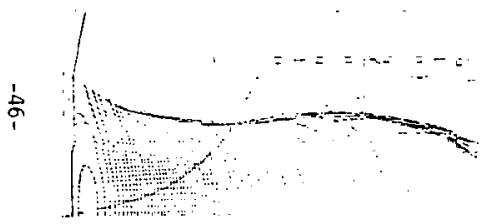

$2.0 \mathrm{MV} 88 \mathrm{kV} 8.769 \mathrm{kA}$

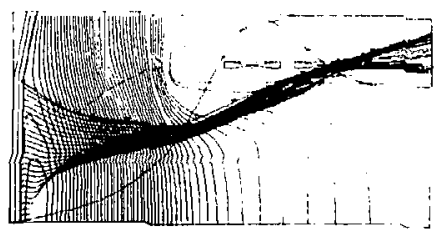

Figure $27 \mathrm{E}$

$2.5 \mathrm{MV}$ Grid $97 \mathrm{kV} 10.12 \mathrm{kA}$

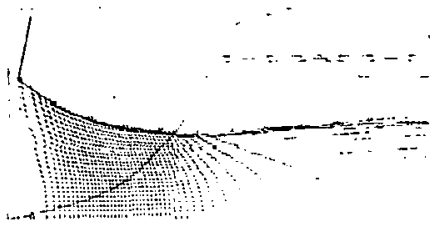

\section{$2.5 \mathrm{MV} 101 \mathrm{kV} 10.76 \mathrm{kA}$}

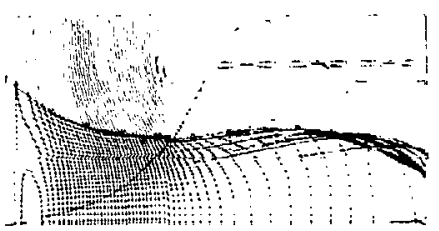

$2.5 \mathrm{MV} 102 \mathrm{kV} 10.92 \mathrm{kA}$

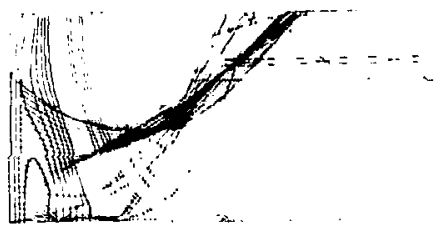

Figure $27 \mathrm{~F}$

$3.0 \mathrm{MV} 110 \mathrm{kV} 12.2 \mathrm{kA}$

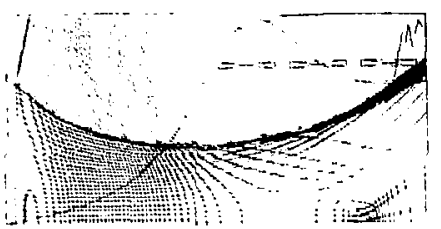

$3.0 \mathrm{MV} 114 \mathrm{kV} 12.87 \mathrm{kA}$

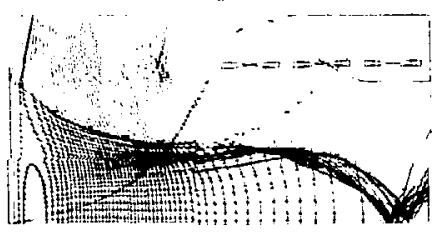

$3.0 \mathrm{MV} 115 \mathrm{kV}$ i3.04 kA

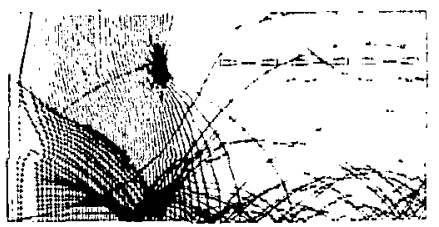

FIGURE $27 \mathrm{D}, \mathrm{E} \& \mathrm{~F}$. Eight inch cathode gun. The anode is $22.4 \mathrm{~cm}$ from the cathode with the washer at $11.2 \mathrm{~cm}$, 
Fìgure $27 \mathrm{G}$
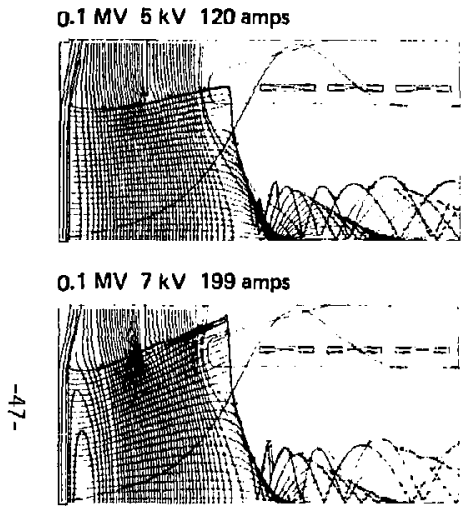

\section{$0.1 \mathrm{MV} 8 \mathrm{kV} 243 \mathrm{mps}$}

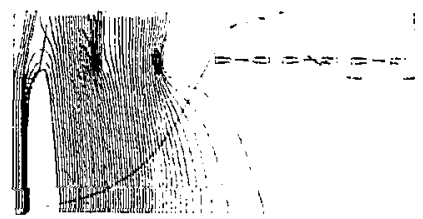

Figure $27 \mathrm{H}$
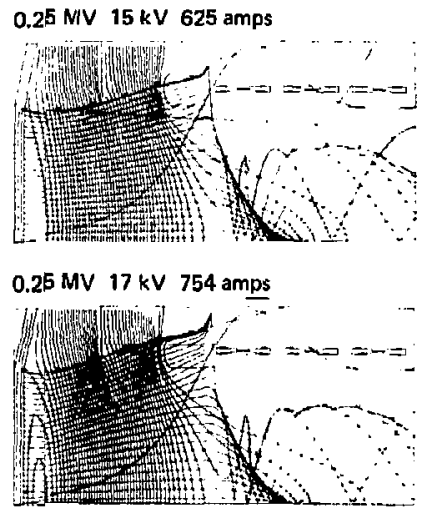

$0.25 \mathrm{MV} 18 \mathrm{kV} 821$ amps

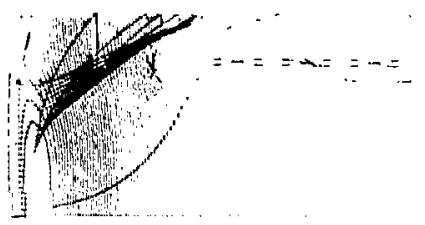

FIGURE $27 \mathrm{G} \& \mathrm{H}$. Eight inch cathode gun. The anode is $22.4 \mathrm{~cm}$ from the cathode with the washer at $11.2 \mathrm{~cm}$. 
$0.5 \mathrm{MV} 30 \mathrm{kV} 1.764 \mathrm{kA}$

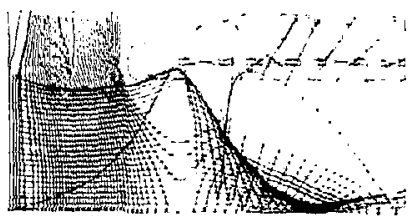

\section{$0.5 \mathrm{MV} 42 \mathrm{kV} 2.915 \mathrm{kA}$}

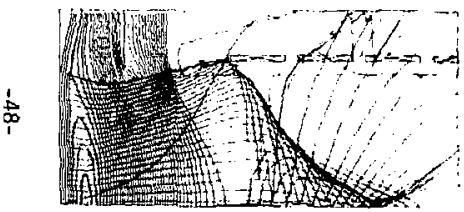

$0.5 \mathrm{MV} 43 \mathrm{kV} 3.019 \mathrm{kA}$

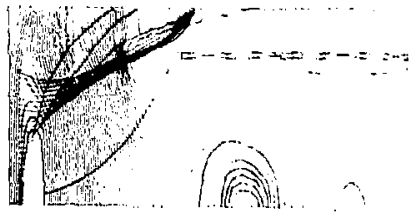

$1.0 \mathrm{MV} 65 \mathrm{kV} 5.589 \mathrm{kA}$

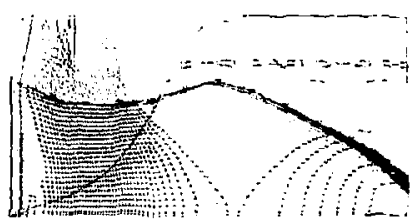

\section{$1,0 \mathrm{MV} 70 \mathrm{kV} 6.242 \mathrm{kA}$}

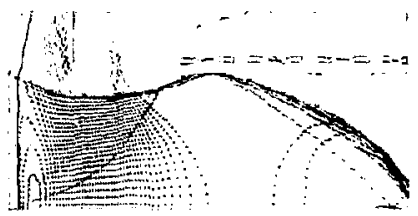

\section{D MV $71 \mathrm{kV} 6.375 \mathrm{kA}$}

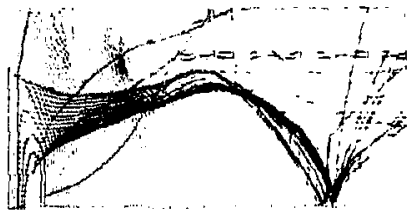

$1.5 \mathrm{MV} 75 \mathrm{kV} 6.916 \mathrm{kA}$

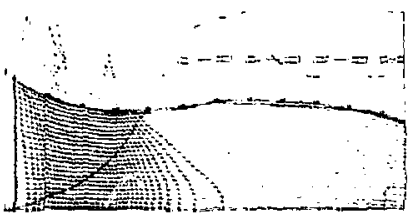

\subsection{92 kV 9.367 kA}

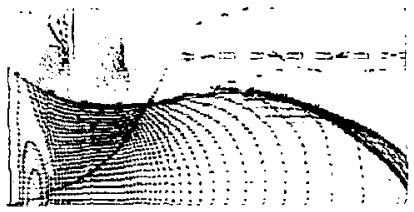

$1.5 \mathrm{MV} 93 \mathrm{kV} 9.519 \mathrm{kA}$

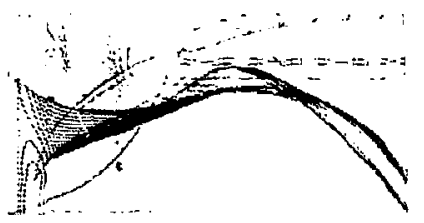

FIGURE $28 \mathrm{~A}$, B \& C. Eight inch cathode gun with anode cathode separation of $18 \mathrm{~cm}$. The washer is placed midway between the cathode and anode. 
Figure $28 \mathrm{D}$
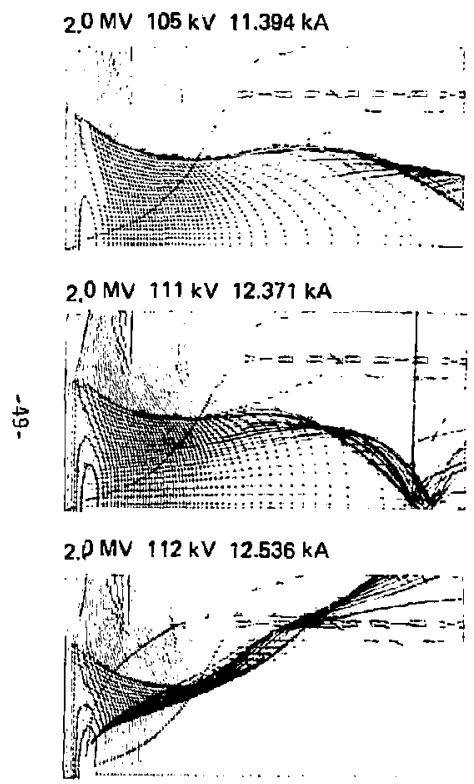

Figure $28 \mathrm{E}$

$2.5 \mathrm{MV} 110 \mathrm{kV} 12.187 \mathrm{kA}$

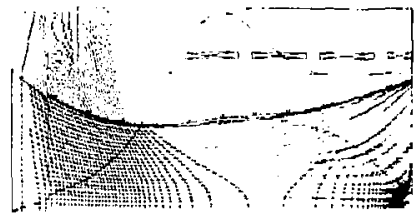

$2.5 \mathrm{MV} 127 \mathrm{kV} 15.079 \mathrm{kA}$

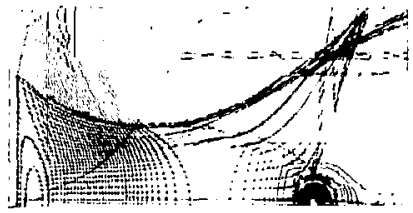

2.5 MV $128 \mathrm{kV} 15.273 \mathrm{kA}$

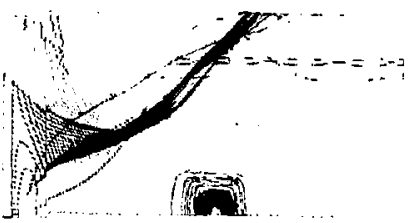

Figure $28 \mathrm{~F}$

$3.0 \mathrm{MV} 136 \mathrm{kV} 16.702 \mathrm{kA}$

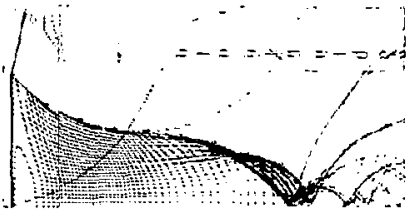

$3.0 \mathrm{MV} 141 \mathrm{kV} 17.616 \mathrm{kA}$

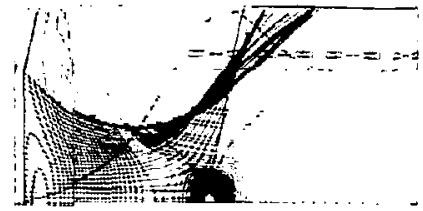

$3.0 \mathrm{MV} 142 \mathrm{kV} 17.801 \mathrm{kA}$

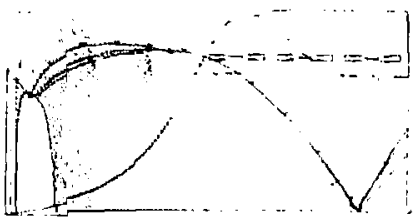

FIGURE 28 D \& E. Eight inch cathode gun with anode cathode separation of $18 \mathrm{~cm}$. The washer is placed midway between the cathode and anode. 
TABLE 1

\begin{tabular}{cccccc}
$\begin{array}{l}\text { Cathode } \\
\text { diameter } \\
\text { (inches) }\end{array}$ & $\begin{array}{c}\text { Anode } \\
\text { position } \\
(\mathrm{cm})\end{array}$ & $\begin{array}{l}\text { Washer } \\
\text { radius } \\
(\mathrm{cm})\end{array}$ & $\begin{array}{c}\text { Washer } \\
\text { position } \\
(\mathrm{cm})\end{array}$ & $\begin{array}{c}\text { Virtual } \\
\text { cathode } \\
\text { grid } \\
\text { voltage }\end{array}$ & $\begin{array}{c}\text { Virtual } \\
\text { cathode } \\
\text { current (kAnp) }\end{array}$ \\
\hline 8 & 18 & 10.16 & 9.82 & $127 / 128$ & $15.097 / 15.273$ \\
- & - & - & none & $110 / 111$ & $12.207 / 12.372$ \\
8 & 22.38 & 10.16 & 11.2 & $110 / 111$ & $12.206 / 12.371$ \\
- & - & - & 13.2 & $101 / 102$ & $10.75 / 10.92$ \\
10 & 18 & - & none & $90 / 91$ & $9.067 / 9.216$ \\
- & - & 12.7 & 9.82 & $106 / 107$ & $16.626 / 16.859$ \\
- & - & - & 11.2 & $107 / 102$ & $15.475 / 15.706$ \\
10 & 22.38 & 12.7 & 11.2 & $92 / 93$ & $13.478 / 13.696$ \\
- & - & - & 13.2 & $92 / 93$ & $14.478 / 14.768$ \\
- & - & - & none & $83 / 84$ & $12.474 / 12.704$ \\
10 & 22.38 & 14.5 & 11.2 & $73 / 74$ & $10.304 / 10.514$
\end{tabular}


IAPLE 2

\begin{tabular}{lcccc}
$\begin{array}{l}\text { Catnoce } \\
\text { diameter } \\
\text { inches }\end{array}$ & $\begin{array}{c}\text { Cathode } \\
\text { anode } \\
\text { separa- } \\
\text { tion } \mathrm{cm}\end{array}$ & $\begin{array}{c}\text { Washer } \\
\text { position } \\
\mathrm{cm}\end{array}$ & $\begin{array}{c}\text { Conductance } \\
\mathrm{a} \\
\mathrm{kA} / \mathrm{MV}\end{array}$ & $\begin{array}{c}\text { Nonlinearity } \\
\mathrm{b} \\
k A / M V 2\end{array}$ \\
\hline 10 & 22.4 & 11.2 & $5.85 \pm .25$ & $0 \pm .125$ \\
10 & 18 & 9.82 & $7.03 \pm .23$ & $-.134 \pm .11$ \\
8 & 22.4 & 13.2 & $4.46 \pm .16$ & $-.048 \pm .077$ \\
8 & 18 & 9.82 & $6.63 \pm .18$ & $-.221 \pm .086$
\end{tabular}

TABLE 3

\begin{tabular}{|c|c|c|c|c|c|c|}
\hline $\begin{array}{l}\text { Cathode } \\
\text { diameter } \\
\text { inches }\end{array}$ & $\begin{array}{c}r_{k} \\
\text { radius } \\
\text { cm }\end{array}$ & $\begin{array}{c}Z_{a} \\
\text { anode } \\
\text { position } \\
c m\end{array}$ & $\begin{array}{c}\text { Radius } \\
\mathrm{Cm}\end{array}$ & $\begin{array}{l}i_{K V} \\
\text { virtual } \\
\text { cathode } \\
\text { threshold }\end{array}$ & $i_{v k} \frac{z_{a}-z_{g}}{r_{k}}$ & $\begin{array}{c}i_{K V} \\
\text { Normalize }\end{array}$ \\
\hline 8 & 10.16 & 22.4 & 10.16 & 10.7 & 22.01 & 1.023 \\
\hline 8 & 10.16 & 18 & 10.16 & 15.2 & 24.68 & 1.147 \\
\hline 10 & 12.7 & 22.4 & 12.7 & 13.12 & 21.59 & 1.003 \\
\hline 7 & 8.89 & 22.4 & 12.7 & 9.29 & 21.84 & 1.075 \\
\hline 5 & 6.35 & 22.4 & 12.7 & 6.89 & 22.68 & 1.054 \\
\hline 3 & 3.81 & 22.4 & 12.7 & 4.79 & 26.27 & 1.221 \\
\hline 10 & 12.7 & 22.4 & 13.2 & 14.62 & 24.06 & 1.118 \\
\hline 10 & 12.7 & 18 & 13.2 & 16.56 & 21.51 & 1 \\
\hline
\end{tabular}


TABLE 4

\begin{tabular}{lcc} 
Anode at $18 \mathrm{~cm}$ & Grid (kV) & Current (kA) \\
\hline & 91 & 13.28 \\
Decelerative threshold & 95 & 14.73 \\
Minimum emittance & 106 & 16.6 \\
Virtual cathode threshold & & \\
& Grid (kV) & Current (kA) \\
Anode at 22.4 cm & 79 & 11.8 \\
\hline & - & - \\
Vecelerative threshoto & 92 & 14.6 \\
Minimum emittance & &
\end{tabular}

TABLE 5

Decekrative Hirtua?

threshold cathode threshold

Ten inc:i (10") cathode, washer

$9.33 k A$

$11.7 \mathrm{kA}$

Ten inch (10") cathode, no washer

6.53

8.17

Seven inch ( $7 "$ ) cathode, no washer

4.57

5.72 
TABLE 6

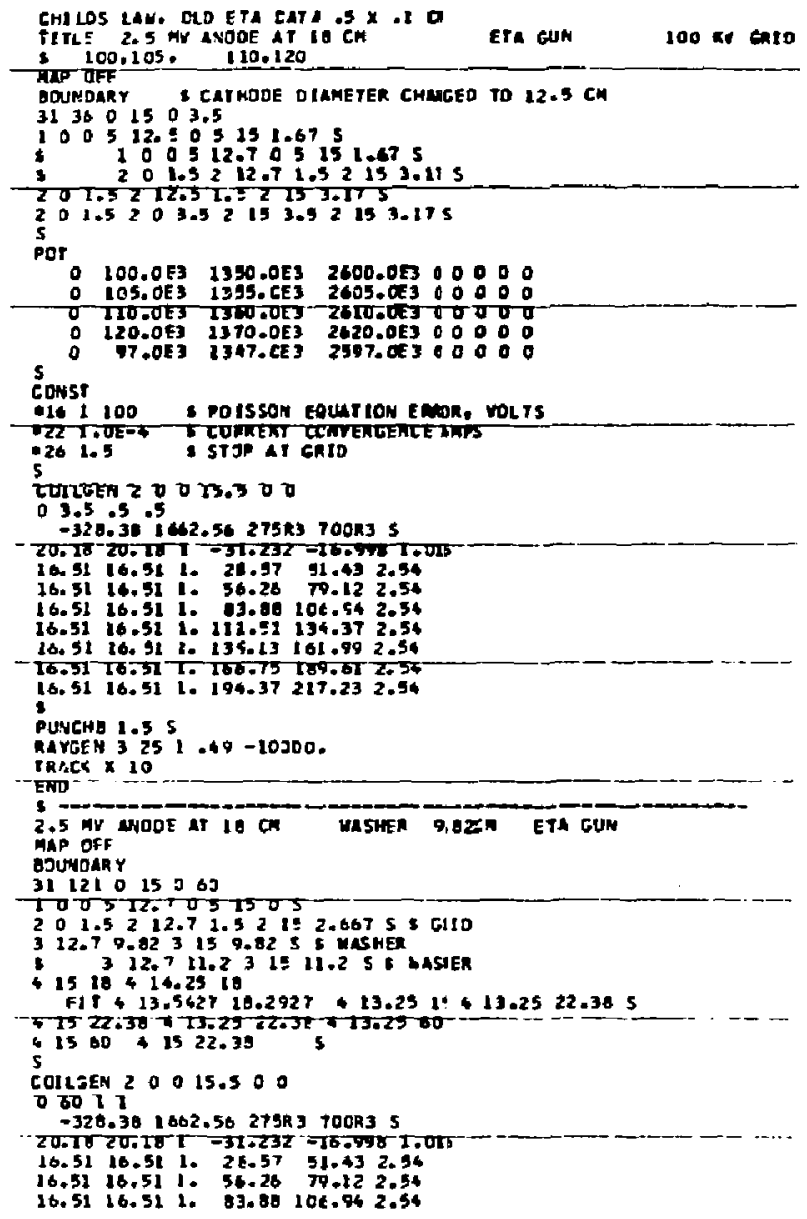

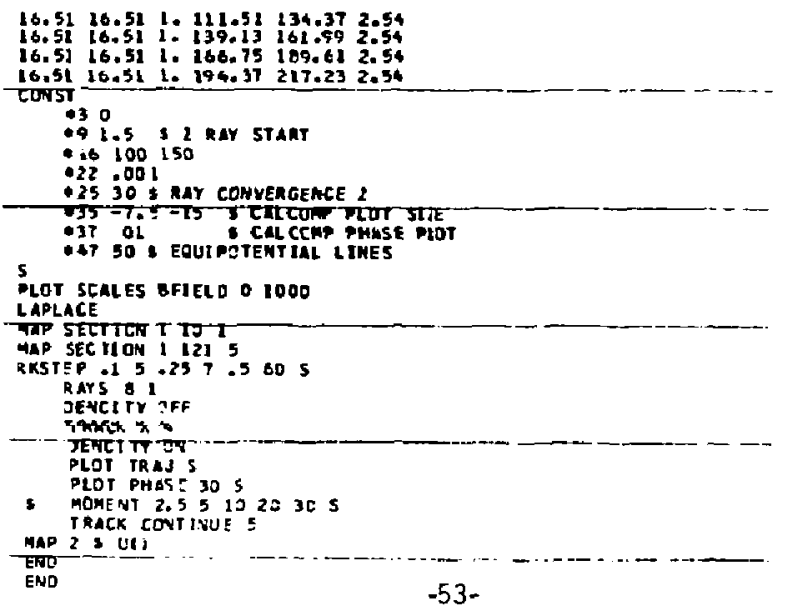




\section{REFERENCES}

1. The Experimental Test Acceleration (ETA), UCRL-85036 (1980)

$T$. J. Fessenden et al.

2. EBQ Code, Transport of Space Change Beams in Axially Symmetric Devices, Arthur C. Paul, UCID-8005 (1978).

3. "Characteristics of the ETA gun", UCRL-84065, A. C. Paul et al, February 1980.

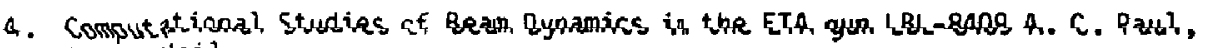
V. K. Neil. 